\title{
Wet-chemical synthesis and applications of non-layer structured two-dimensional nanomaterials
}

\author{
Chaoliang $\operatorname{Tan}^{1} \&$ Hua Zhang ${ }^{1}$
}

Non-layer structured nanomaterials with single- or few-layer thickness have two-dimensional sheet-like structures and possess intriguing properties. Recent years have seen major advances in development of a host of non-layer structured ultrathin two-dimensional nanomaterials such as noble metals, metal oxides and metal chalcogenides. The wet-chemical synthesis has emerged as the most promising route towards high-yield and mass production of such nanomaterials. These nanomaterials are now finding increasing applications in a wide range of areas including catalysis, energy production and storage, sensor and nanotherapy, to name but a few.

$\mathrm{S}$ ince the exfoliation and identification of graphene in 2004 (ref. 1), layered ultrathin two-dimensional (2D) nanomaterials have been the subject of intensive study over the last decade $^{2-5}$. Ultrathin $2 \mathrm{D}$ nanomaterials are sheet-like structures with single- or few-layer thickness (typically less than $5 \mathrm{~nm}$ ), but lateral size larger than $100 \mathrm{~nm}$ or even up to tens of micrometres. Till now, besides graphene ${ }^{1,2,6}$, a large number of graphene-like ultrathin $2 \mathrm{D}$ nanomaterials, such as transition metal dichalcogenides, layered metal oxides, transition metal carbides and layered-double hydroxides, have been prepared via various methods ${ }^{3-5,7-12}$. Owing to the ultrahigh specific surface area and strong quantum confinement of electrons in two dimensions, these ultrathin 2D nanomaterials display many unconventional physical, optical, chemical and electronic properties. They have also shown great potential in various applications such as electronic devices ${ }^{1,13-15}$, catalysis $^{16-18}$, energy storage and conversion ${ }^{19,20}$, sensing ${ }^{21,22}$ and biomedicine $e^{23}$.

Layered compounds are those that possess strong lateral chemical bonding in planes but display weak van der Waals interaction between planes. One typical example is graphite that consists of weakly stacked graphene sheets forming three-dimensional (3D) bulk crystals. However, many other materials form atomic bonding in three dimensions (for example, metals), reflecting the non-layered nature of their bulk crystals. Inspired by the layered ultrathin $2 \mathrm{D}$ crystals, one can also anticipate that controlled synthesis of non-layer structured 2D materials may bring up some unique properties and advanced functions that cannot be achieved for their counterparts in other dimensionalities. A host of non-layer structured ultrathin 2D nanomaterials, such as noble metals (for example, $\mathrm{Au}, \mathrm{Pd}$ and $\mathrm{Rh}$ ), metal oxides (for example, $\mathrm{TiO}_{2}, \mathrm{WO}_{3}, \mathrm{CeO}_{2}, \mathrm{In}_{2} \mathrm{O}_{3}, \mathrm{SnO}_{2}, \mathrm{Fe}_{2} \mathrm{O}_{3}$ and so on) and metal chalcogenides (for example, PbS, $\mathrm{CuS}$, CuSe, SnSe, ZnSe, ZnS, CdSe and so on), have been prepared over the last few years; almost 
all of these non-layer structured ultrathin 2D nanomaterials are synthesized using wet-chemical synthesis approaches. Expectedly, the synthesized 2D nanomaterials offer some unique advantages in comparison with their counterparts in other dimensionalities and hold great promises in a variety of applications, such as catalysis, supercapacitors, photodetectors and photothermal therapy. Although many reviews on ultrathin 2D nanomaterials are available in the literature ${ }^{2-7,9-12}$, almost all of them focus on the layered $2 \mathrm{D}$ crystals. Therefore, a timely, comprehensive review on non-layer-structured $2 \mathrm{D}$ nanomaterials is of great importance for the future study.

In this review, we aim to give an overview on the recent progress of wet-chemical synthesis and applications of non-layer structured 2D nanomaterials such as metals, metal oxides and metal chalcogenides. We first introduce various types of wet-chemical synthesis strategies for preparation of non-layer structured 2D nanomaterials including 2D-templated synthesis, hydro/solvothermal synthesis, self-assembly of low-dimensional nanocrystals and soft colloidal templated synthesis. Then some promising applications, especially in catalysis, of the synthesized 2D nanomaterials are briefly described, with emphasis on those with excellent performance. Finally, a summary of current research status and progress, along with some personal perspectives on the challenges and future research directions in this promising area, are given.

\section{Wet-chemical synthesis method and structure characterization}

Till now, a variety of synthetic strategies, such as mechanical exfoliation ${ }^{1,24-26}$, liquid exfoliation ${ }^{5,27-30}$, ion-intercalation and exfoliation $^{5,31-35}$, chemical vapour deposition (CVD) ${ }^{36-40}$ and wet-chemical synthesis ${ }^{41-48}$, have been developed for preparation of ultrathin 2D nanomaterials. The comparison of some typical methods for synthesis of ultrathin $2 \mathrm{D}$ nanomaterials is summarized in Table 1.

The mechanical exfoliation technique that was first used to produce graphene is the typical approach for producing single- or few-layer nanosheets from their corresponding layered bulk crystals ${ }^{1,24-26}$. The pristine $2 \mathrm{D}$ crystals (for example, graphene and $\mathrm{MoS}_{2}$ ) obtained by this approach often show high quality and large lateral size, which are ideal for investigation of their intrinsic properties and fabrication of electronic devices. However, the low throughput at the current form limits their practical applications. Consequently, as a promising alternative, liquid exfoliation by direct sonication of layered bulk crystals in solvents or surfactant/ polymer solutions was developed to produce ultrathin $2 \mathrm{D}$ nanomaterials in high yield and large scale ${ }^{5,27-30}$. However, the yield of single-layer sheets produced by this method is low and it is hard to separate the single-layer sheets from the solution. Alternatively, the ion-intercalation and exfoliation method was developed towards the high-yield and large-scale production of single-layer nanosheets, such as graphene, $\mathrm{MoS}_{2}, \mathrm{TiS}_{2}, \mathrm{TaS}_{2}, \mathrm{WS}_{2}$, $\mathrm{ZrS}_{2}, h-\mathrm{BN}$ and so on ${ }^{5,31-35}$. However, the $2 \mathrm{D}$ nanosheets obtained by this method might possess many defects and relatively small lateral size, and this approach is also very sensitive to water and oxygen. It should be noted that all aforementioned exfoliation methods are only applicable to those materials whose bulk crystals are layered.

In addition to these exfoliation methods, CVD method is another appealing strategy for growth of high-quality singlecrystalline $2 \mathrm{D}$ sheets on substrates with scalable size, controllable thickness and excellent electronic properties ${ }^{36-40}$. However, the CVD method suffers from the requirement of high temperature, high vacuum and specific substrates. Wet-chemical synthesis has been emerging as a very promising alternative towards the high-yield, low-cost and mass production of all types of ultrathin 2D nanosheets in the solution phase ${ }^{41-48}$. Particularly, almost all the non-layer structured ultrathin 2D nanomaterials, such as metals, metal chalcogenides and metal oxides, can be synthesized using wet-chemical synthesis methods because of their non-layered nature.

Meanwhile, along with the development of nanotechnology, some useful and powerful techniques have been identified or developed for characterization of these non-layer structured $2 \mathrm{D}$ nanomaterials. For example, the commonly used techniques for characterization of traditional nanomaterials, such as scanning electron microscopy (SEM), transmission electron microscopy, $\mathrm{X}$-ray diffraction, atomic force microscopy, Raman spectroscopy, energy-dispersive X-ray spectroscopy and X-ray photoelectron spectroscopy, have been used to characterize the size, thickness, crystallinities, exposed crystal facets, compositions and structures of these ultrathin 2D nanomaterials. The X-ray absorption fine structure spectroscopy is another powerful technique to study the local atomic geometry and chemical state of atoms of one specific element in the ultrathin 2D materials, allowing for understanding

Table 1 | Comparison of the typical synthetic methods for 2D nanomaterials.

\begin{tabular}{|c|c|c|c|c|}
\hline Method & Brief description of the method & Advantage & Disadvantage & Ref. \\
\hline $\begin{array}{l}\text { Mechanical } \\
\text { exfoliation }\end{array}$ & $\begin{array}{l}\text { Adhesive Scotch tape is used to peel layered bulk } \\
\text { crystals. The peeled flakes are then deposit on a target } \\
\text { substrate to get single- or few-layer sheets }\end{array}$ & $\begin{array}{l}\text { High quality, large } \\
\text { lateral size, few defects, } \\
\text { simplicity }\end{array}$ & Low yield, non-massive production & $1,24-26$ \\
\hline $\begin{array}{l}\text { Liquid } \\
\text { exfoliation }\end{array}$ & $\begin{array}{l}\text { Direct sonication of layered bulk crystals in solvents or } \\
\text { in presence of surfactants or polymers }\end{array}$ & $\begin{array}{l}\text { Solution processibility, } \\
\text { massive production, low } \\
\text { cost, simplicity }\end{array}$ & $\begin{array}{l}\text { Low yield of single layers, uncontrollable } \\
\text { layer number, relatively small lateral size }\end{array}$ & $5,27-30$ \\
\hline $\begin{array}{l}\text { lon- } \\
\text { intercalation } \\
\text { and exfoliation }\end{array}$ & $\begin{array}{l}\text { Intercalation of layered bulk compounds with } \mathrm{Li} \text { or } \mathrm{Na} \\
\text { ions with subsequent sonication in solution }\end{array}$ & $\begin{array}{l}\text { Solution processibility, } \\
\text { massive production, } \\
\text { high yield of } \\
\text { monolayers }\end{array}$ & $\begin{array}{l}\text { Relatively small lateral size with possible } \\
\text { defects and phase transformation, the } \\
\text { procedure sensitive to water and oxygen }\end{array}$ & $5,31-35$ \\
\hline $\begin{array}{l}\text { Chemical } \\
\text { vapour } \\
\text { deposition }\end{array}$ & $\begin{array}{l}\text { One or more volatile precursors react and/or } \\
\text { decompose on the exposed substrate surface to } \\
\text { produce 2D crystals at high temperature and high } \\
\text { vacuum }\end{array}$ & $\begin{array}{l}\text { High quality, large } \\
\text { lateral size, controllable } \\
\text { thickness, few defects }\end{array}$ & $\begin{array}{l}\text { High temperature, high vacuum, relatively } \\
\text { complicated experiments, high cost }\end{array}$ & $36-40$ \\
\hline $\begin{array}{l}\text { Wet-chemical } \\
\text { synthesis }\end{array}$ & $\begin{array}{l}\text { Direct synthesis in the solution phase assisted with } \\
\text { surfactants or polymers }\end{array}$ & $\begin{array}{l}\text { Solution processibility, } \\
\text { high yield, massive } \\
\text { production }\end{array}$ & $\begin{array}{l}\text { Surfactants required, hard to obtain } \\
\text { uniform single-layer nanosheets }\end{array}$ & $41-48$ \\
\hline
\end{tabular}


the defects, vacancies and doping effects ${ }^{12}$. In this section, we focus on several main wet-chemical synthesis methods including 2D-templated synthesis, hydro/solvothermal synthesis, selfassembly of low-dimensional nanocrystals and soft colloidal templated synthesis. We give examples of synthesis of non-layerstructured 2D nanomaterials along with their characterization by various techniques. The summary of the dimension, synthesis methods and used characterization techniques of these non-layerstructured 2D nanomaterials are shown in Table 2.

2D-templated synthesis. Templated synthesis methods have been widely used for growth of anisotropic nanocrystals (for example, nanowires $)^{49,50}$, in which the crystal growth can be confined in specific dimension. Non-layer structured 2D nanomaterials can be synthesized using prepared $2 \mathrm{D}$ nanomaterials as templates ${ }^{51-58}$. As a typical example, our group prepared $\mathrm{Au}$ square nanosheets (AuSSs) with thickness of $\sim 2.4 \mathrm{~nm}(\sim 16 \mathrm{Au}$ atomic layers) and size of $200-500 \mathrm{~nm}$ by reducing $\mathrm{HAuCl}_{4}$ with 1 -amino-9-octadecene on graphene oxide template (Fig. 1a) ${ }^{51}$. As can be seen, this AuSS crystal owns unique hexagonal-close packed $(h c p)$ phase rather than the common face-centred cubic $(f c c)$ phase. This is the first time that the pure $h c p \mathrm{Au}$ nanostructure, which can be stable under ambient conditions, has been synthesized. Furthermore, thick Au sheets can be obtained via a secondary growth by using this hcp AuSS as the seed and a phase transformation from $h c p$ to $f c c$ was observed during the secondary growth process ${ }^{52}$. The centre of resultant thick $\mathrm{Au}$ sheets has an alternating $h c p / f c c$ structural domain, while the edge site is defect-free $f c c$ structure. Significantly, our group has also demonstrated recently that the further coating of Ag thin layer on the hcp AuSSs could induce the phase transformation to obtain (100) $)_{\mathrm{f}}$-oriented $f c c$ Au@Ag core-shell square sheets or $(110)_{\mathrm{h}} /(101)_{\mathrm{f}}$-oriented $h c p / f c c$ Au@Ag square sheets $^{53}$. Similarly, the further growth of $\mathrm{Pt}$ or Pd thin layer on AuSSs also could induce the phase transformation from the hcp to $f c c$ structures to form core-shell Au@Pt or Au@Pd nanoplates ${ }^{54}$. However, unlike the coating of Ag, the coating of Pt or Pd on $h c p$ AuSSs mainly leads to the formation of $f c c$ Au@Pt or Au@Pd rhombic nanoplates with $(101)_{\mathrm{f}}$ orientation, although a little amount of $f c c(100)_{\mathrm{f}}$-oriented Au@Pt and Au@Pd square nanoplates can also be observed. It is believed that the large lattice mismatch between $\mathrm{Pt}$ or $\mathrm{Pd}$ and $\mathrm{Au}$ compared with $\mathrm{Ag}$ is responsible for the formation of unprecedented (101) f $_{\mathrm{f}}$-oriented core-shell nanoplates. More interestingly, the complete phase transformation of AuSSs from $h c p$ to $f c c$ structures was realized via the simple ligand exchange under ambient conditions at room temperature ${ }^{53}$. By simply replacing the oleylamine capped on AuSSs with thiol molecules, the hcp AuSSs can be transformed into (100) $)_{\mathrm{f}}$-oriented $f c c$ AuSSs (ref. 53). Interestingly, Wei and coworkers $^{55}$ recently developed a $\mathrm{CuO}$ nanoplate-templated method to synthesize freestanding half-unit-cell $\alpha-\mathrm{Fe}_{2} \mathrm{O}_{3}$ nanosheets. The layered iron hydroxide nanosheets were first prepared on the $\mathrm{CuO}$ template surface. Then the $\mathrm{CuO}$ template was slowly etched away to get the freestanding iron hydroxide nanosheets. Finally, an annealing treatment was carried out to transform the iron hydroxide sheets into freestanding $\alpha$ $\mathrm{Fe}_{2} \mathrm{O}_{3}$ nanosheets with size of up to $\sim 1 \mu \mathrm{m}$ and thickness of $0.55-0.59 \mathrm{~nm}$ (Fig. 1b,c).

The used templates (for example, graphene oxide and $\mathrm{CuO}$ ) in the aforementioned examples are inert during the synthesis process. Recently, our group reported the use of semiconductor nanosheets (for example, CuSe and $\mathrm{CuS}$ ) as reactive templates to prepare novel 2D nanostructures ${ }^{56,57}$. For example, by using the synthesized $\mathrm{CuS}$ nanosheet with thickness of $\sim 4.8 \mathrm{~nm}$ as the reactive template, a series of copper-based ternary and quaternary

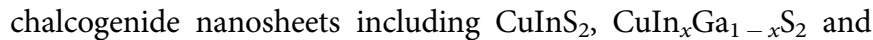
$\mathrm{Cu}_{2} \mathrm{ZnSnS}_{4}$ were successfully prepared via the cation exchange process (Fig. 1d,e) ${ }^{56}$. The shape and size of nanosheets did not undergo significant changes during the transformation process. All the resultant ternary and quaternary semiconductor nanosheets have uniform size, shape and thickness. In addition, our group also demonstrated that semiconductor nanosheets (for example, $\mathrm{Cu}_{2-x} \mathrm{Se}$ and $\mathrm{Cu}_{1.97} \mathrm{~S}$ ) with different crystal phases can be synthesized via phase transformation by using as-prepared nanosheets (for example, CuSe and $\mathrm{CuS}$ ) as templates ${ }^{5}$. Briefly, the synthesized hexagonal-phased $\mathrm{CuSe}$ nanosheets were transformed into cubic-phased $\mathrm{Cu}_{2-x} \mathrm{Se}$ nanosheets by simply heating treatment in presence of $\mathrm{Cu}^{\mathrm{I}}$ cations. Both the $\mathrm{CuSe}$ and $\mathrm{Cu}_{2-x} \mathrm{Se}$ nanosheets have similar morphologies with size up to micrometre and thickness of $\sim 5 \mathrm{~nm}$ (Fig. 1f,g). Notably, a similar transformation from the ultrathin hexagonal-phased $\mathrm{CuS}$ nanosheets to cubic-phased $\mathrm{Cu}_{1.97} \mathrm{~S}$ nanosheets can also be realized by using this method. In addition, $\mathrm{Li}$ and co-workers demonstrated the synthesis of $\mathrm{NiO}$ nanosheets with size of up to micrometre and thickness of $<2 \mathrm{~nm}$ from layered $\alpha-\mathrm{Ni}(\mathrm{OH})_{2}$ nanosheets through a simple annealing treatment ${ }^{58}$.

Hydro/solvothermal synthesis. Hydro/solvothermal synthesis is another typical method that has been widely used for synthesis of non-layer structured 2D nanomaterials ${ }^{59-67}$. As a typical example, $\mathrm{Li}$ and co-workers demonstrated the synthesis of poly (vinylpyrrolidone) (PVP)-supported single-layer rhodium (Rh) nanosheets with edge length of $500-600 \mathrm{~nm}$ and thickness of $\sim 0.4 \mathrm{~nm}$ via a facile solvothermal route (Fig. $2 \mathrm{a}-\mathrm{c})^{59}$. This is the first time for synthesis of single-layer atomic metal nanostructures in the liquid phase. In addition, Dou and coworkers developed a generalized solvothermal method for the synthesis of a series of metal oxide nanosheets, including $\mathrm{TiO}_{2}$, $\mathrm{ZnO}, \mathrm{Co}_{3} \mathrm{O}_{4}, \mathrm{WO}_{3}, \mathrm{Fe}_{3} \mathrm{O}_{4}$ and $\mathrm{MnO}_{2}$ (Fig. $2 \mathrm{~d}-\mathrm{f}$ ) ${ }^{60}$. The size of the $\mathrm{TiO}_{2}$ nanosheets is $\sim 200 \mathrm{~nm}$, while the sizes of $\mathrm{ZnO}, \mathrm{Co}_{3} \mathrm{O}_{4}$ and $\mathrm{WO}_{3}$ are up to $1-10 \mu \mathrm{m}$. Similarly, the thickness of these metal oxide nanosheets varied between 1.6 and $5.2 \mathrm{~nm}$, corresponding to 2-7 stacking layers of the monolayer.

In addition, Xie and co-workers used hydro/solvothermal method to synthesize several kinds of non-layer structured 2D nanosheets including $\mathrm{ZnSe}, \mathrm{ZnS}, \mathrm{CeO}_{2}, \mathrm{In}_{2} \mathrm{O}_{3}, \mathrm{SnO}_{2}, \mathrm{Co}_{9} \mathrm{Se}_{8}$ and $\mathrm{Co}_{9} \mathrm{~S}_{8}$-oleylamine hybrid ${ }^{61-66}$. For instance, to synthesize $\mathrm{ZnSe}$ and $\mathrm{ZnS}$ nanosheets, the lamellar organic-inorganic intermediates, for example, $\left(\mathrm{Zn}_{2} \mathrm{Se}_{2}\right)(n$-propylamine $)$ and $\left(\mathrm{Zn}_{2} \mathrm{~S}_{2}\right)$ (n-propylamine), were first synthesized using a solvothermal method ${ }^{61}$. Then the hybrid intermediates were exfoliated by sonication to get freestanding ultrathin $\mathrm{ZnSe}$ and $\mathrm{ZnS}$ nanosheets, respectively. The resultant $\mathrm{ZnSe}$ nanosheets possess a lateral size of $\sim 500 \mathrm{~nm}$ and thickness of $\sim 0.9 \mathrm{~nm}$ (Fig. 2g,h). Similarly, Zhang and co-workers reported the preparation of CdS nanosheets with size of $300-800 \mathrm{~nm}$ and thickness of $\sim 4 \mathrm{~nm}$ via a similar strategy by using the diethylenetriamine (DETA) as the surfactant ${ }^{67}$. Moreover, Xie and co-workers reported that atomically thin $\mathrm{CeO}_{2}$ sheets with surface-confined pits could be prepared by a hydrothermal method combined with the subsequent thermal annealing treatment ${ }^{62}$. Briefly, $\mathrm{CeCO}_{3} \mathrm{OH}$ sheets were first synthesized from cerium chloride using sodium oleate as the surfactant via a hydrothermal method. Then the intermediate sheets were transformed into ultrathin $\mathrm{CeO}_{2}$ sheets with surface-confined pits having a thickness of $\sim 0.6 \mathrm{~nm}$ via a thermal annealing treatment (Fig. 2i). Besides, ultrathin $\mathrm{In}_{2} \mathrm{O}_{3}$ porous sheets with rich oxygen vacancies were also successfully synthesized via a similar hydrothermal method with subsequent thermal annealing process 63 . 
Table 2 | List of non-layer structured 2D nanomaterials.

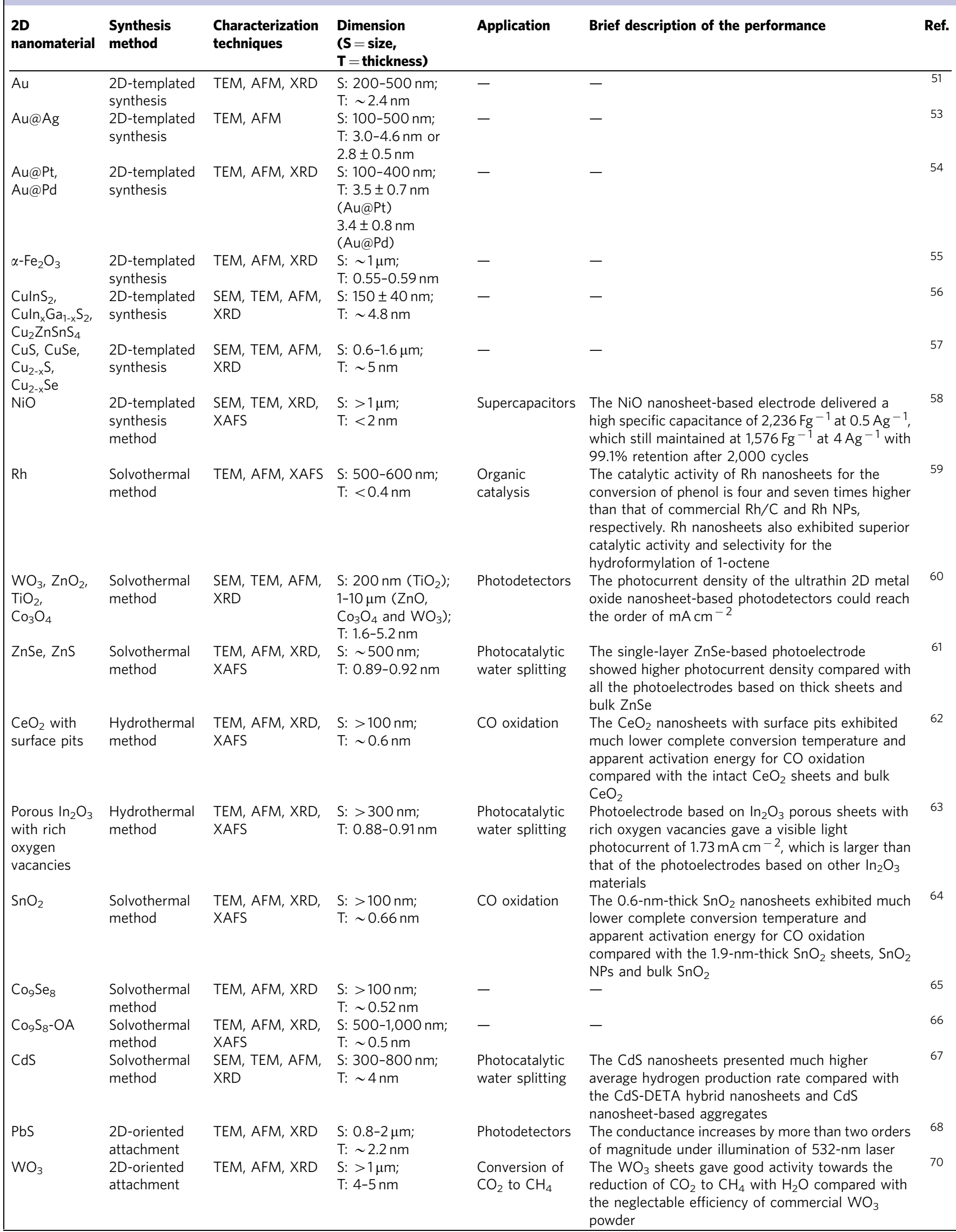




\begin{tabular}{|c|c|c|c|c|c|}
\hline $\begin{array}{l}\text { 2D } \\
\text { nanomaterial }\end{array}$ & $\begin{array}{l}\text { Synthesis } \\
\text { method }\end{array}$ & $\begin{array}{l}\text { Characterization } \\
\text { techniques }\end{array}$ & $\begin{array}{l}\text { Dimension } \\
\text { (S= size, } \\
\mathbf{T}=\text { thickness) } \\
\end{array}$ & Application & Brief description of the performance \\
\hline $\mathrm{Au}$ & $\begin{array}{l}\text { Assembly of } \\
\text { NPs }\end{array}$ & TEM, AFM, & $\begin{array}{l}\mathrm{S}: 200-1,000 \mathrm{~nm} ; \\
\mathrm{T}: \sim 1.68 \mathrm{~nm}\end{array}$ & - & - \\
\hline $\mathrm{Eu}_{2} \mathrm{O}_{3}$ & $\begin{array}{l}\text { Assembly of } \\
\text { nanowires }\end{array}$ & TEM, AFM, XRD & $\begin{array}{l}\text { S: } 200 \mathrm{~nm}-10 \mu \mathrm{m} ; \\
\mathrm{T}: \sim 3.8 \mathrm{~nm}\end{array}$ & - & - \\
\hline $\mathrm{PbS}$ & $\begin{array}{l}\text { Assembly of } \\
\text { nanowires }\end{array}$ & TEM, AFM & $\begin{array}{l}\text { S: } 200-250 \mathrm{~nm} \text { in } \\
\text { width and } 3-20 \mu \mathrm{m} \\
\text { in length; } \\
\mathrm{T:} \sim 1.8 \mathrm{~nm}\end{array}$ & - & - \\
\hline CdSe & $\begin{array}{l}\text { Soft colloidal } \\
\text { templated } \\
\text { synthesis }\end{array}$ & TEM, AFM, XRD & $\begin{array}{l}\text { S: } 200-300 \mathrm{~nm} \text { in } \\
\text { length and } \\
\sim 100 \mathrm{~nm} \text { in width; } \\
\mathrm{T}: \sim 1.4 \mathrm{~nm}\end{array}$ & - & - \\
\hline CuS & $\begin{array}{l}\text { Soft colloidal- } \\
\text { templated } \\
\text { synthesis }\end{array}$ & $\begin{array}{l}\text { SEM, TEM, AFM, } \\
\text { XRD }\end{array}$ & $\begin{array}{l}\text { S: } 453 \pm 6 \mathrm{~nm} ; \mathrm{T}: \\
3.2 \pm 0.2 \mathrm{~nm}\end{array}$ & Li ion batteries & $\begin{array}{l}\text { The CuS electrode exhibited a large discharge and } \\
\text { charge capacity of at } 0.2 \mathrm{Ag}-1 \text {, which higher than } \\
\text { that of other CuS nanostructures. It also showed } \\
\text { good cycling stability }\end{array}$ \\
\hline $\mathrm{SnSe}$ & $\begin{array}{l}\text { Colloidal } \\
\text { synthesis }\end{array}$ & $\begin{array}{l}\text { SEM, TEM, AFM, } \\
\text { XRD }\end{array}$ & $\begin{array}{l}\mathrm{S}: 300 \mathrm{~nm} ; \\
\mathrm{T}: \sim 1 \mathrm{~nm}\end{array}$ & - & - \\
\hline $\mathrm{Gd}_{2} \mathrm{O}_{3}$ & $\begin{array}{l}\text { Colloidal } \\
\text { synthesis }\end{array}$ & TEM, XRD & $\begin{array}{l}\mathrm{S}: \sim 200 \mathrm{~nm} ; \\
\mathrm{T}:<1 \mathrm{~nm}\end{array}$ & - & - \\
\hline$\beta-\mathrm{Co}(\mathrm{OH})_{2}$ & $\begin{array}{l}\text { Liquid-phase } \\
\text { synthesis }\end{array}$ & $\begin{array}{l}\text { TEM, AFM, XRD, } \\
\text { XAFS }\end{array}$ & $\begin{array}{l}\text { S: } 100-400 \mathrm{~nm} ; \\
\text { T: } 0.46-0.48 \mathrm{~nm}\end{array}$ & Supercapacitors & $\begin{array}{l}\text { The fabricated } \beta \text {-Co }(\mathrm{OH})_{2} \text {-based cell delivered high } \\
\text { specific capacitances of } 241.9 \text { and } 219.6 \mathrm{Fg}^{-1} \text { at the } \\
\text { current density of } 1 \text { and } 20 \mathrm{Ag}^{-1} \text {, respectively. It } \\
\text { also showed excellent stability }\end{array}$ \\
\hline \multirow[t]{2}{*}{$\mathrm{Pd}$} & $\begin{array}{l}\text { CO-confined } \\
\text { growth }\end{array}$ & TEM, AFM, XRD & $\begin{array}{l}\mathrm{S}: 20-160 \mathrm{~nm} ; \\
\mathrm{T}: \sim 1.8 \mathrm{~nm}\end{array}$ & $\begin{array}{l}\text { Oxidation of } \\
\text { formic acid }\end{array}$ & $\begin{array}{l}\text { The current density of the Pd nanosheets for formic } \\
\text { acid oxidation is } \sim 2.5 \text { times as active as that of } \\
\text { commercial palladium black catalyst }\end{array}$ \\
\hline & & & & $\begin{array}{l}\text { Photothermal } \\
\text { therapy }\end{array}$ & $\begin{array}{l}\text { The temperature of aqueous solution with small } \\
\text { amount of Pd nanosheets significantly increased } \\
\text { under irradiation by a NIR laser }\end{array}$ \\
\hline
\end{tabular}

AFM, atomic force microscopy; 2D, two-dimensional; DETA, diethylenetriamine; NIR, near-infrared; NP, nanoparticle; OA, oleylamine; SEM, scanning electron microscopy; TEM, transmission electron microscopy; XAFS, X-ray absorption fine structure spectroscopy; XRD, X-ray diffraction.

Self-assembly of low-dimensional nanocrystals. Self-assembly of low-dimensional nanocrystals (for example, nanoparticles (NPs) and nanowires) is also a promising alterative way to prepare ultrathin $2 \mathrm{D}$ nanomaterials ${ }^{68-73}$. Generally, the fusion of lowdimensional nanocrystals occurs during the assembly process to form $2 \mathrm{D}$ nanomaterials. As a typical example, Weller and coworkers used a typical self-assembly strategy, that is, 2D-oriented attachment, to prepare ultrathin $\mathrm{PbS}$ nanosheets with size of $0.8-2 \mu \mathrm{m}$ and thickness of $\sim 2.2 \mathrm{~nm}$ from tiny PbS NPs (ref. 68). The ordered and densely packed ligand layers of oleic acid on $\{100\}$ surface of PbS NPs can drive the 2D-oriented attachment of $\mathrm{PbS}$ NPs to form large sheets. The chlorine-containing solvents in the initial nucleation and growth process of nanocrystals are also essential in the orientated attachment process. The $2 \mathrm{D}$-oriented attachment is an entropy-driven crystal growth and reconstruction process, which minimizes high-surface-energy facets and interfaces between NPs, leading to the coalescence of NPs to form a large crystal. The formation mechanism was further confirmed by Wang and co-workers using the in situ small and wide-angle synchrotron X-ray scattering on the same spot of sample under pressure coupled with transmission electron microscopy ${ }^{69}$. Recently, single-crystalline $\mathrm{WO}_{3}$ nanosheets with thickness of $4-5 \mathrm{~nm}$ and lateral size up to micrometre have also been constructed via $2 \mathrm{D}$-oriented attachment of tiny $\mathrm{WO}_{3}$ nanocrystals with size of $4-5 \mathrm{~nm}$ (ref. 70). As an alternative, $\mathrm{Lu}$ and co-workers demonstrated the self-assembly of $\mathrm{Au}$ nanoclusters into ultrathin nanosheets with single-cluster thickness ${ }^{71}$. The as-prepared $\mathrm{Au}_{15}$ clusters in a mixed solvent of dibenzyl ether and liquid paraffin were simply annealed at
$140{ }^{\circ} \mathrm{C}$ to evaporate solvents to form assembled $\mathrm{Au}$ sheets at the interface. The assembled Au sheet with width of $\sim 300 \mathrm{~nm}$ and length of $200-1,000 \mathrm{~nm}$ is consistent of Au clusters rather than a single-crystal structure.

In addition to NPs, the assembly of nanowires into ultrathin $2 \mathrm{D}$ nanosheets has been also achieved recently ${ }^{72,73}$. For example, Yao and co-workers reported the synthesis of $\mathrm{Eu}_{2} \mathrm{O}_{3}$ nanosheets from the assembly of $\mathrm{Eu}_{2} \mathrm{O}_{3}$ nanowires with diameter of $\sim 1.5 \mathrm{~nm}$ (ref. 72). The $\mathrm{Eu}_{2} \mathrm{O}_{3}$ nanowire bundles in 1,5-pentanediol were transferred into water solution and soaked for different time. Then they were assembled in sheet-like porous structures after 3-5 min soaking, and further transformed to rectangle nanosheets when the soaking time increased to $1 \mathrm{~h}$. The thickness of resultant sheets is $\sim 3.8 \mathrm{~nm}$. The lateral size of $\mathrm{Eu}_{2} \mathrm{O}_{3}$ sheets can be tuned from several hundreds of nanometres to $10 \mu \mathrm{m}$ by simply controlling the soaking time of nanowires. With similar strategy, Acharya et al. ${ }^{73}$ demonstrated the assembly of ultrathin PbS nanowires into $2 \mathrm{D}$ nanosheets with regular rectangular shape of 200-250 in width, 3-20 $\mu \mathrm{m}$ in length and $\sim 1.8 \mathrm{~nm}$ in thickness. The as-prepared $\mathrm{PbS}$ nanowires with diameter of $\sim 1.8 \mathrm{~nm}$ were assembled and fused together to form sheet structure via a collective coalescence approach at the air-water interface.

Soft colloidal templated synthesis and other methods. Generally, soft colloidal templated synthesis represents a type of oil phase-based methods ${ }^{74,75}$, in which the long-chain oleyl amine and/or oleic acid surfactants are used as the soft colloidal templates for directing the crystal growth. Recently, the soft 


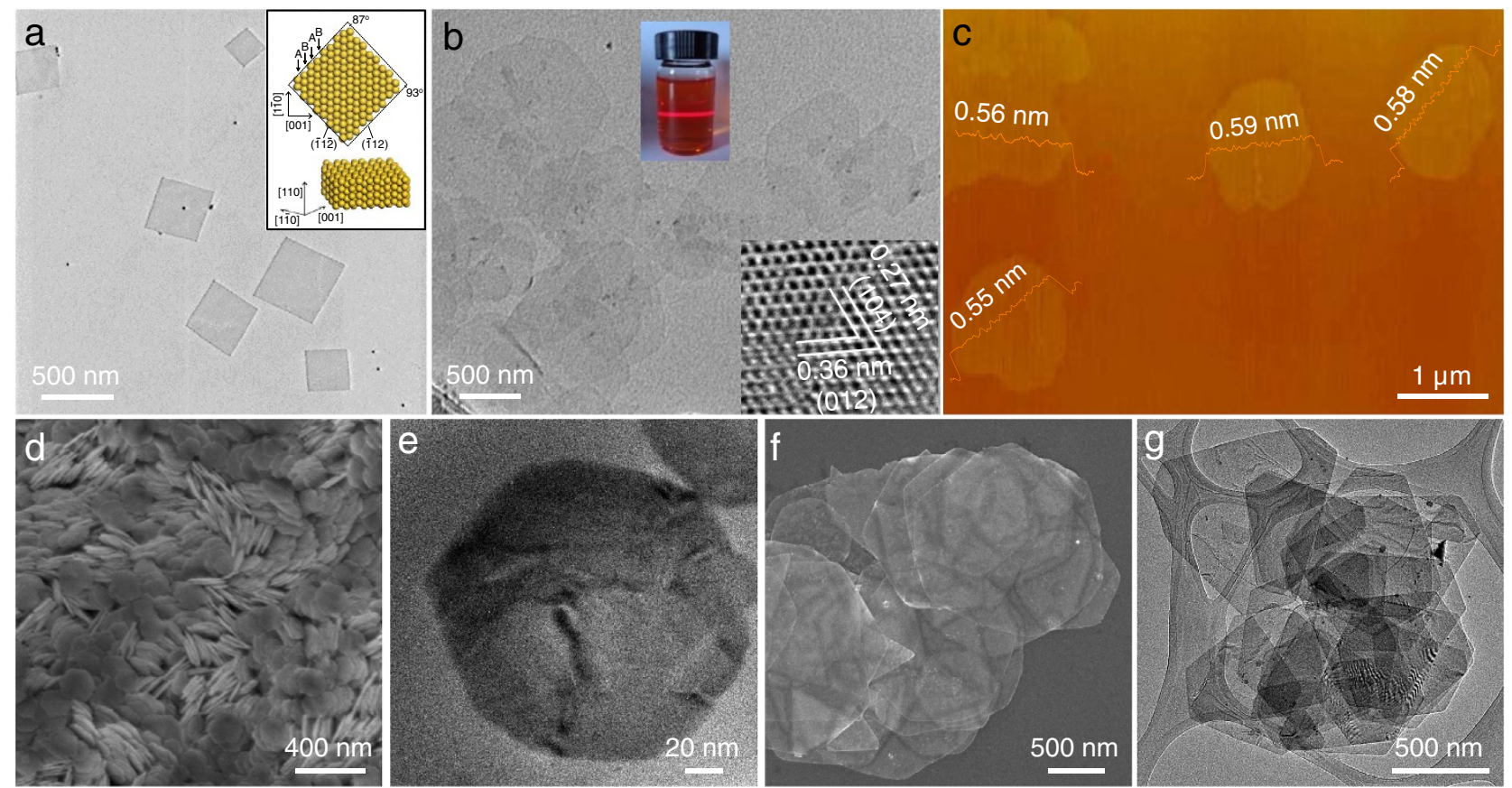

Figure 1 | 2D nanosheets synthesized using the 2D-templated synthesis method. (a) TEM images of hcp AuSSs. Inset: crystallographic models for a typical AuSS with its basal plane along the [110]h zone axis, showing ABAB stacking along the [001]h direction. Adapted from ref. 51 (b) TEM image of $\alpha-\mathrm{Fe}_{2} \mathrm{O}_{3}$ nanosheets. Inset: HRTEM image and Tyndall effect of $\alpha-\mathrm{Fe}_{2} \mathrm{O}_{3}$ nanosheets. Adapted, with permission, from ref. 55 (copyright 2014 American Chemical Society). (c) Atomic force microscopy (AFM) image of $\alpha-\mathrm{Fe}_{2} \mathrm{O}_{3}$ nanosheets. Adapted, with permission, from ref. 55. (Copyright 2014, American Chemical Society). (d) SEM and (e) TEM images of CulnS 2 nanosheets. Reproduced, with permission, from ref. 56 (C) 2014 John Wiley \& Sons Inc). (f) TEM and (g) SEM images of CuSe and $\mathrm{Cu}_{2-x}$ Se nanosheets, respectively. Reproduced, with permission, from ref. 57 (C) 2014 John Wiley \& Sons Inc).

colloidal templated synthesis has been employed for preparation of ultrathin $2 \mathrm{D}$ nanocrystals, especially for semiconductors ${ }^{76,77}$. In 2009, Hyeon and co-workers used this method to synthesize wurtzite ultrathin $\mathrm{CdSe}$ nanosheets ${ }^{76}$. It is supposed that intermediate lamellar complexes composed of $2 \mathrm{D}$ arrays of $\mathrm{CdCl}_{2}$ and alkyl amine or/and oleic acid were first obtained, in which the alkyl amine or/and oleic acid served as the soft colloidal template. Then the intermediate lamellar complex further reacted with the Se source to form stacked CdSe nanosheets. It was found that well-separated ultrathin CdSe nanosheets can be obtained by using the mixture of alkyl amine and oleic acid as the soft template in contrast to the use of single long-chain surfactant (for example, alkyl amine or oleic acid). The resultant single-layer CdSe sheets possess length of $200-300 \mathrm{~nm}$, width of $\sim 100 \mathrm{~nm}$ and thickness of $\sim 1.4 \mathrm{~nm}$. Recently, our group reported the generalized synthesis of ultrathin metal sulphide nanocrystals by using the soft colloidal templated strategy ${ }^{77}$. Ultrathin $\mathrm{CuS}$ nanosheets with thickness of $\sim 3.2 \mathrm{~nm}$ (two unit cells) were prepared in gram amount (Fig. 3a-c). The resultant $\mathrm{CuS}$ nanosheets have regular hexagonal shape with lateral size up to $\sim 453 \mathrm{~nm}$ (Fig. 3a,b).

Some other wet-chemical methods have also been developed for synthesis of ultrathin 2D nanostructures, which cannot be categorized into the aforementioned methods ${ }^{78-81}$. As a typical example, Wang and co-workers presented a one-pot synthetic method for synthesis of single-layer SnSe nanosheets in oil phase $^{78}$. The 1,10-phenanthroline was used as the morphology control agent, which played a crucial role in controlling the morphology of SnSe nanocrystals. The obtained SnSe nanosheets have lateral size of $\sim 300$ and thickness of $\sim 1.0 \mathrm{~nm}$ (Fig. 3d,e). As another example, Yan and co-workers synthesized several ultrathin rare-earth oxide nanosheets in the oil phase in presence of ionic liquid salts ${ }^{79}$. Two types of $\mathrm{Gd}_{2} \mathrm{O}_{3}$ nanosheets with widths of 100 and $200 \mathrm{~nm}$ and thicknesses of 0.35 and $0.65 \mathrm{~nm}$, respectively, were synthesized. Besides, this general method can also be extended to prepared $\mathrm{Ho}_{2} \mathrm{O}_{3}$ and $\mathrm{Y}_{2} \mathrm{O}_{3}$ nanosheets with thicknesses less than $1 \mathrm{~nm}$. Very recently, Xie and co-workers demonstrated that the synthesis of single-layer $\beta-\mathrm{Co}(\mathrm{OH})_{2}$ nanosheets can be achieved by a simple and green approach under ambient atmospheric conditions using cobalt chloride and aminoethanol as precursors ${ }^{80}$. As an interesting example, Zheng and co-workers reported a CO-confined growth method to synthesize freestanding ultrathin hexagonal $\mathrm{Pd}$ nanosheets with thickness less than 10 atomic layers $(\sim 1.8 \mathrm{~nm})$ and controllable edge length from 20 to $160 \mathrm{~nm}$ (Fig. 3f ${ }^{81}$. The use of $\mathrm{CO}$ as the capping agent is essential for the growth of Pd nanocrystals, which were confined in $2 \mathrm{D}$ because of its strong adsorption on the basal (111) planes of $\mathrm{Pd}$ nanosheets.

Applications of the non-layer structured 2D nanomaterials Owing to their large lateral size and ultrathin thickness, 2D nanomaterials possess ultrahigh specific surface area $^{82}$, and thus are ideal candidates for surface-active applications. For instance, ultrathin $2 \mathrm{D}$ nanomaterials have been proved to be fascinating platforms for engineering high-efficient catalysts for various kinds of catalytic applications ${ }^{83,84}$. It was found that some of the synthesized ultrathin $2 \mathrm{D}$ nanosheets have excellent activities in a number of catalytic processes. In addition, the ultrahigh surface area of $2 \mathrm{D}$ nanomaterials also makes them very promising electrode materials for supercapacitors and photodetectors. In this section, we will discuss the synthesized ultrathin $2 \mathrm{D}$ nanomaterials for various applications including catalysis, supercapacitors, photodetectors and photothermal therapy, with emphasis on those materials with excellent performance. The summary of the non-layer structured 2D nanomaterials for different applications is made in Table 2. 


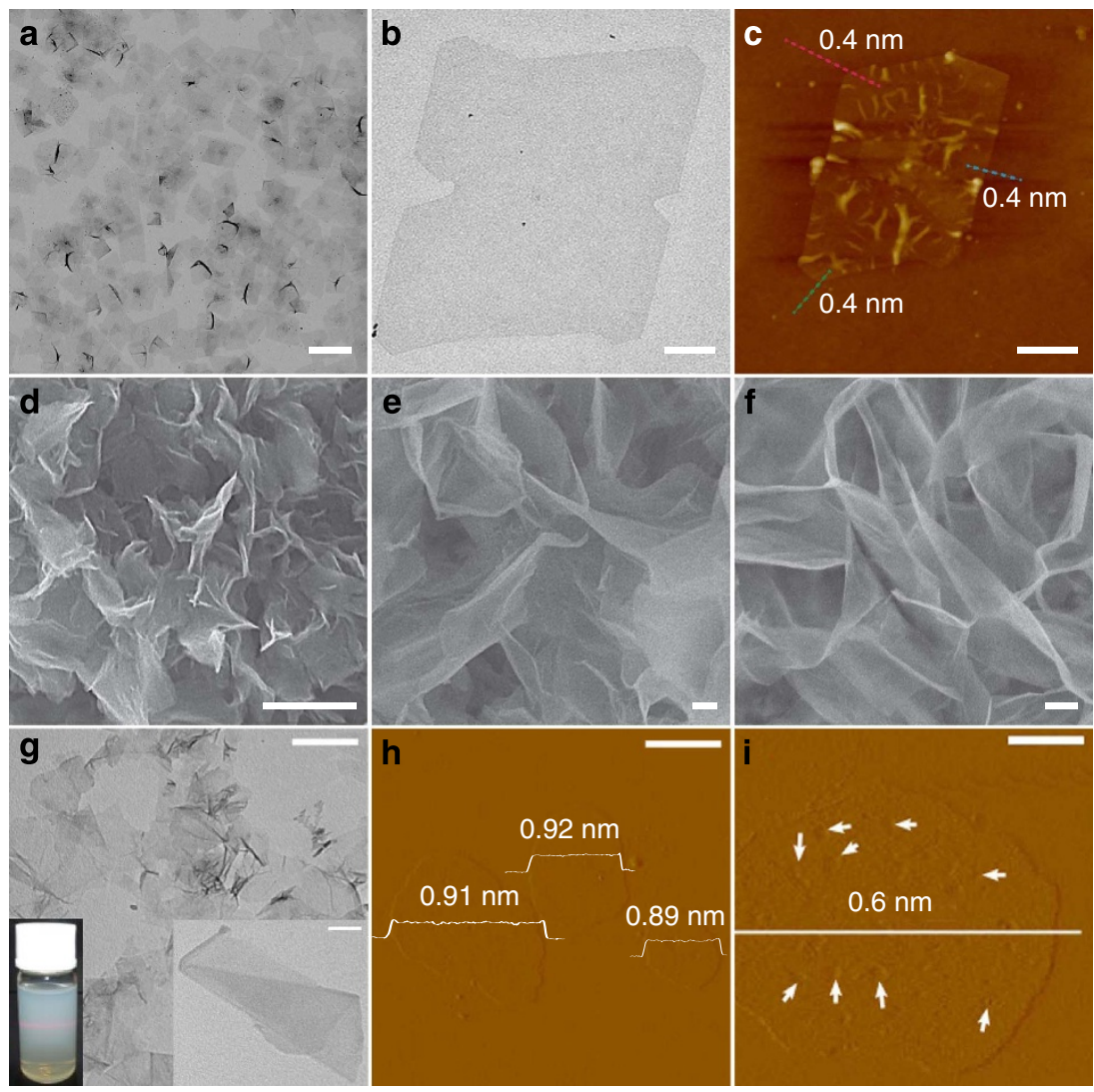

Figure 2 | 2D nanosheets synthesized using the hydro/solvothermal synthesis method. (a,b) TEM image of the PVP-capped Rh nanosheets, and (c) AFM image of a bare Rh nanosheet. Adapted from ref. 59. (d) SEM images of $2 \mathrm{D}$ nanosheets of $\mathrm{TiO}_{2}, \mathrm{ZnO}_{(\mathbf{e})}$ and $\mathrm{Co}_{3} \mathrm{O}_{4}(\mathbf{f} ; \mathrm{scale}$ bars, $200 \mathrm{~nm}$ ). Adapted from ref. 60. (g) TEM image of ZnSe single layers (scale bar, $500 \mathrm{~nm}$ ). Inset: the enlarged TEM image (scale bar, $100 \mathrm{~nm}$ ) and Tyndall effect of ZnSe single layers. Adapted from ref. 61. (h) AFM image ZnSe single layers (scale bar, $500 \mathrm{~nm}$ ). Adapted from ref. 61. (i) AFM image of ultrathin surface-pitted $\mathrm{CeO}_{2}$ sheets (scale bars, $100 \mathrm{~nm}$ ). Adapted from ref. 62.
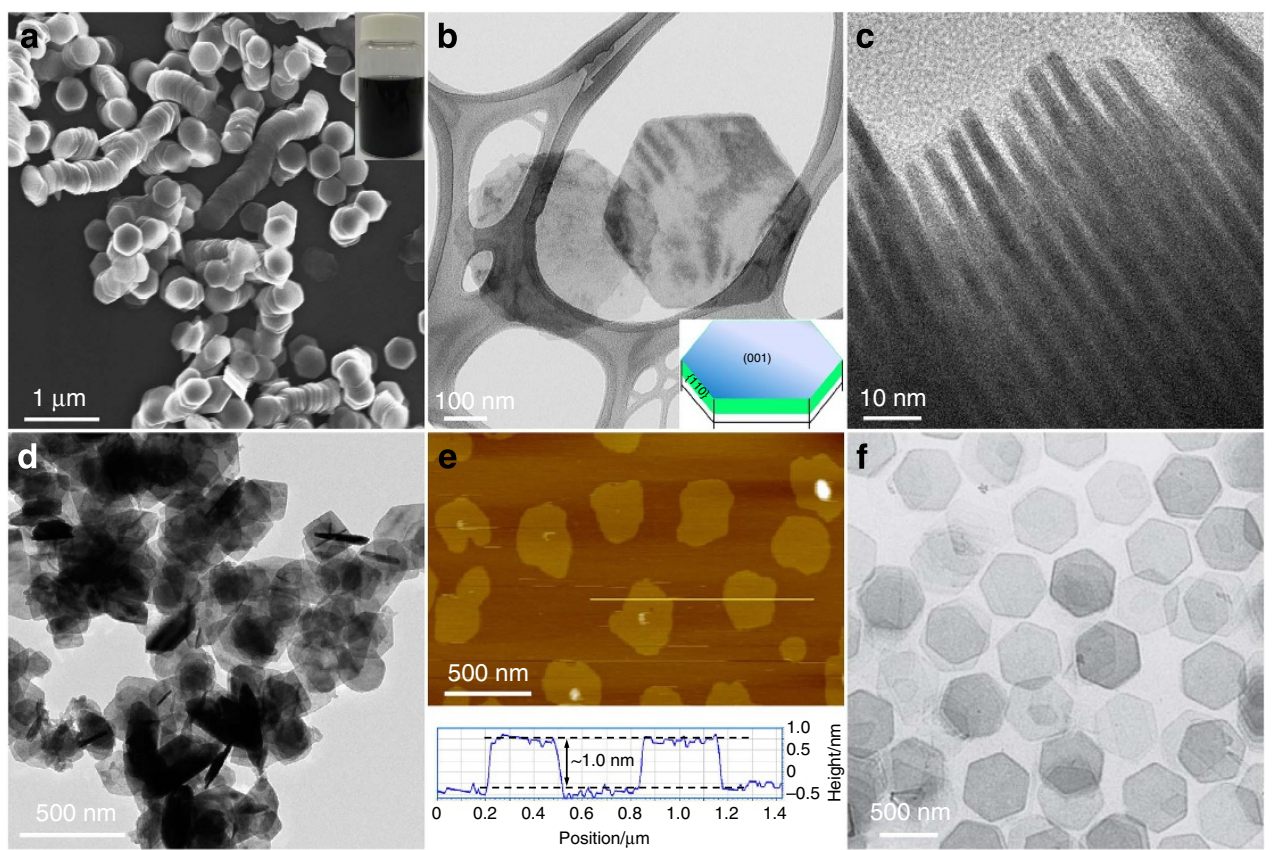

Figure 3 | 2D nanosheets synthesized using soft colloidal templated synthesis and other methods. (a) SEM image of ultrathin CuS nanosheets. Inset: photograph of the colloid solution of CuS nanosheets. Adapted from ref. 77. TEM images of ultrathin CuS nanosheets with (b) lying flat and (c) standing on the TEM grids. Inset in b: scheme of an ultrathin CUS nanosheet. Adapted from ref. 77. (d) TEM and (e) AFM images of SnSe nanosheets. Adapted, with permission, from ref. 78 (Copyright 2013 American Chemical Society). (f) TEM image of Pd nanosheets. Adapted from ref. 81. 
Organic catalytic reactions. $\mathrm{Li}$ and co-workers demonstrated that the single-layer $\mathrm{Rh}$ nanosheets could be a high-efficient catalyst for catalytic hydrogenation and hydroformylation reactions (Fig. 4a,b) ${ }^{59}$. Hydrogenation of phenol and hydroformylation of 1 -octene were used as probe reactions to investigate the catalytic properties of PVP-capped $\mathrm{Rh}$ nanosheets. The PVP-capped Rh sheets gave $>99.9 \%$ conversion within $4 \mathrm{~h}$ at near room temperature $\left(30^{\circ} \mathrm{C}\right)$ under low $\mathrm{H}_{2}$ pressure for hydrogenation of phenol. The catalytic activity of conversion at $1 \mathrm{~h}$ is seven and four times higher than those of PVP-capped Rh $\mathrm{NPs}$ and commercial $\mathrm{Rh} / \mathrm{C}$, respectively. In the hydroformylation of 1-octene, the PVP-capped Rh nanosheets also exhibited both superior catalytic activity and selectivity towards the target product (aldehyde) under mild reaction conditions. The excellent catalytic properties make the ultrathin $\mathrm{Rh}$ nanosheets a promising catalyst for catalytic organic reactions. It is well known that the surface atom ratio is a key factor in catalysis. Owing to its singlelayer feature, the ratio of the surface $\mathrm{Rh}$ atom in $\mathrm{Rh}$ nanosheets is $100 \%$. As a result, the largely enhanced catalytic activity could be ascribed to the full exposure of $\mathrm{Rh}$ atoms in the $\mathrm{Rh}$ nanosheets.

Electrocatalytic oxidation of formic acid. It was found that the $\mathrm{Pd}$ nanosheets could be highly efficient in electrocatalysis for oxidation of formic acid ${ }^{81}$. Owing to its high specific surface area, the measured electrochemically active surface area of $\mathrm{Pd}$ nanosheets with edge length of $41 \mathrm{~nm}$ was calculated to be as high as $67 \mathrm{~m}^{2} \mathrm{~g}^{-1}$, which is slightly lower than the theoretically calculated maximum surface area $\left(\sim 100 \mathrm{~m}^{2} \mathrm{~g}^{-1}\right)$. The experimental results indicated that the $\mathrm{Pd}$ nanosheets have excellent electrocatalytic activity for the oxidation of formic acid. The current density of Pd nanosheets for formic acid oxidation was measured to be $1,380 \mathrm{~mA} \mathrm{mg}^{-1}$ at $0.14 \mathrm{~V}$, which is much higher ( $\sim 2.5$ times) than that of the commercial palladium black catalyst.

Photocatalytic water splitting. The ultrathin $\mathrm{ZnSe}$ nanosheet has been identified to be a promising catalyst for photoelectronchemical (PEC) solar water splitting ${ }^{61}$. By simply spin-coating $\mathrm{ZnSe}$ single layers, few atom-thick $\mathrm{ZnSe}$ sheets and bulk $\mathrm{ZnSe}$ on a polyethylene terephthalate substrate, flexible and transparent photoelectrodes were fabricated for water photocatalysis. All ZnSe-based photoelectrodes gave a very low current density $\left(<5 \mu \mathrm{A} \mathrm{cm}^{-2}\right)$ under the scan from -0.4 to $0.8 \mathrm{~V}$ in dark. Note that the single-layer $\mathrm{ZnSe}$ sheet-based photoelectrode showed photocurrent density of $2.14 \mathrm{~mA} \mathrm{~cm}^{-2}$ at $0.72 \mathrm{~V}$ under the irradiation of $300 \mathrm{~W}$ Xe lamp, which is higher than that of all other ZnSe-based photoelectrodes, and roughly 195 times higher than that of the bulk counterpart. Moreover, the $\mathrm{ZnSe}$ sheets also exhibited strong intensity and frequency-dependent photocurrent density. Compared with the $\mathrm{ZnSe}$ quantum dots with average size of 3-4 nm, the single-layer ZnSe nanosheets also showed much higher photocurrent density at $0.72 \mathrm{~V}$, further confirming its strikingly efficient PEC water splitting. Similarly, it was found that the ultrathin porous $\operatorname{In}_{2} \mathrm{O}_{3}$ nanosheets with rich oxygen vacancy also presented superior performance compared with ultrathin porous $\mathrm{In}_{2} \mathrm{O}_{3}$ sheets with poor oxygen vacancy and bulk $\mathrm{In}_{2} \mathrm{O}_{3}$ when they were used as photoelectrodes in visible light PEC cells ${ }^{63}$.

Recently, Zhang and co-workers demonstrated that the ultrathin CdS nanosheets could be used as an efficient photocatalyst for hydrogen generation ${ }^{67}$. For comparison, the

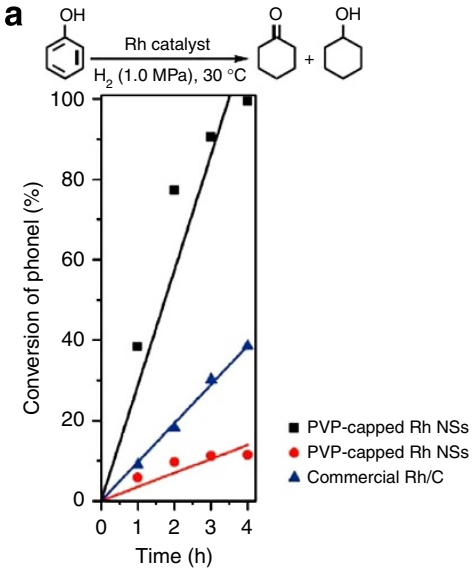

C

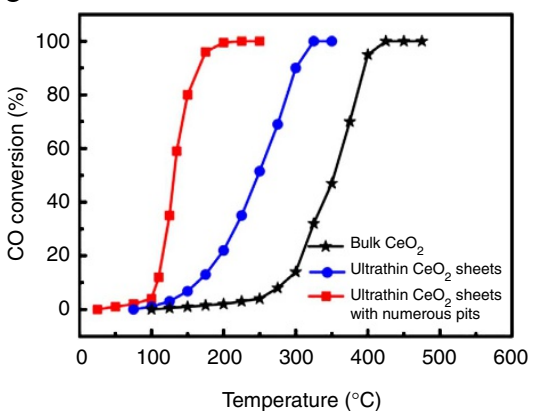

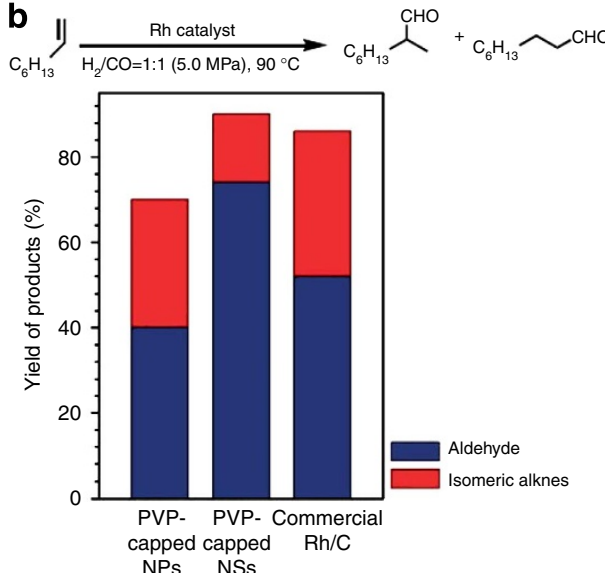

d

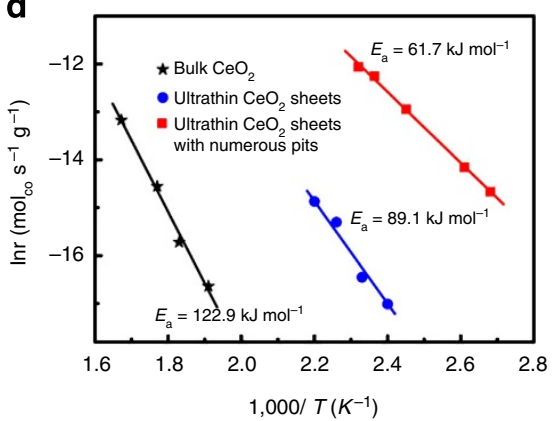

Figure 4 | Catalytic activities of $\mathbf{R h}$ and $\mathbf{C e O}_{\mathbf{2}}$ nanosheets. (a) Hydrogenation of phenol and (b) hydroformylation of 1-octene. Adapted from ref. 59. (c) The reaction temperature-dependent catalytic activities of $\mathrm{CeO}_{2}$-based catalysts for $\mathrm{CO}$ oxidation (experimental error: $\pm 3 \%$ ), and (d) the corresponding Arrhenius plot for the three $\mathrm{CeO}_{2}$-based samples (experimental error: $\pm 3 \%$ ). Adapted from ref. 62 . 
photocatalytic activities of some other CdS-based samples including CdS-DETA hybrid nanosheets, CdS nanosheet-based aggregates and CdS NPs were also studied. The average hydrogen production rate of CdS nanosheets reached $41.1 \mathrm{mmol} \mathrm{h}^{-1} \mathrm{~g}^{-1}$, which is strikingly higher than that of the CdS-DETA hybrid nanosheets $\left(7.5 \mathrm{mmol} \mathrm{h}^{-1} \mathrm{~g}^{-1}\right)$, CdS nanosheet-based aggregates $\left(6.7 \mathrm{mmol} \mathrm{h}^{-1} \mathrm{~g}^{-1}\right)$, and CdS NPs (negligible). The apparent quantum efficiency of ultrathin CdS nanosheets was determined to be $1.38 \%$ at $420 \mathrm{~nm}$. It was found that loading of small amount of PbS NPs (1 wt\%) on CdS nanosheets can further significantly enhance the quantum efficiency to as high as $9.62 \%$. Note that no obvious decrease in the $\mathrm{H}_{2}$ production rate was observed even after 12-h $\mathrm{H}_{2}$ evolution, indicating the good stability of catalyst.

Catalytic CO oxidation. Xie and co-workers reported that the ultrathin $\mathrm{CeO}_{2}$ nanosheets with $\sim 20 \%$ surface pits could be used as a high-efficiency catalyst for $\mathrm{CO}$ oxidation $^{62}$. The pit-confined $\mathrm{CeO}_{2}$ nanosheets presented $50 \%$ conversion of $\mathrm{CO}$ to $\mathrm{CO}_{2}$ at $131^{\circ} \mathrm{C}$, which is much lower than that of the intact $\mathrm{CeO}_{2}$ sheets $\left(248^{\circ} \mathrm{C}\right)$ and bulk counterpart $\left(345^{\circ} \mathrm{C}\right.$; Fig. $\left.4 \mathrm{c}\right)$. At $131^{\circ} \mathrm{C}$, the conversion ratio of intact $\mathrm{CeO}_{2}$ sheets and bulk crystals is only 3.2 and $0.89 \%$, respectively. The temperature for these $\mathrm{CeO}_{2}$ nanosheets with surface pits used to completely convert $\mathrm{CO}$ to $\mathrm{CO}_{2}$ in the $\mathrm{CO}$ oxidation is $\sim 200^{\circ} \mathrm{C}$, which is also lower than those for $\mathrm{CeO}_{2}$ nanosheets $\left(325^{\circ} \mathrm{C}\right)$ and bulk materials $\left(425^{\circ} \mathrm{C}\right.$; Fig. 4c). It is worth pointing out that the catalytic property of these ultrathin pit-confined $\mathrm{CeO}_{2}$ nanosheets is the best so far among all reported $\mathrm{CeO}_{2}$-based catalysts for $\mathrm{CO}$ oxidation. In addition to the conversion temperature, the apparent activation energy of catalyst is another important parameter used for evaluation of $\mathrm{CO}$ oxidation. Significantly, the apparent activation energy of $\mathrm{CeO}_{2}$ nanosheets with numerous surface pits is $61.7 \mathrm{~kJ} \mathrm{~mol}^{-1}$, while that for $\mathrm{CeO}_{2}$ nanosheets and bulk counterpart is 89.1 and $122.9 \mathrm{~kJ} \mathrm{~mol}^{-1}$, respectively (Fig. 4d). The structural analysis of $\mathrm{CeO}_{2}$ nanosheets with surface pits revealed that the Ce sites have average coordination number of 4.6, indicating the unsaturated coordination nature of $\mathrm{Ce}$ at pit sites. The superior catalytic performance of the $\mathrm{CeO}_{2}$ nanosheets with numerous surface pits is attributed to the unsaturatedcoordinated pit-surrounding Ce sites. According to the theoretical calculation, the four-coordinated and five-coordinated Ce sites are the more active sites for $\mathrm{CO}$ catalytic oxidation. In this case, The $\mathrm{CeO}_{2}$ sheets with these sites possess strikingly lower apparent activation energy in comparison with the other two $\mathrm{CeO}_{2}$ samples, resulting in the much lower conversion temperature for $\mathrm{CO}$ oxidation.

In addition, the same group demonstrated that the ultrathin $\mathrm{SnO}_{2}$ nanosheets with thickness of $0.6 \mathrm{~nm}$ also present excellent performance for the $\mathrm{CO}$ catalytic oxidation ${ }^{64}$. The ignition temperature used for single-layer $\mathrm{SnO}_{2}$ nanosheets with conversion ratio of $\sim 10 \%$ for $\mathrm{CO}$ oxidation is $124^{\circ} \mathrm{C}$, while for other counterparts it is much higher, that is, $203^{\circ} \mathrm{C}$ for 1.9-nm-thick $\mathrm{SnO}_{2}$ nanosheets, $270{ }^{\circ} \mathrm{C}$ for $\mathrm{SnO}_{2} \mathrm{NPs}$ and $360^{\circ} \mathrm{C}$ for bulk $\mathrm{SnO}_{2}$. More importantly, the conversion temperature of 0.6-nm-thick $\mathrm{SnO}_{2}$ nanosheets is $165^{\circ} \mathrm{C}$, which is much lower than that of the 1.9-nm-thick $\mathrm{SnO}_{2}$ sheets $\left(330^{\circ} \mathrm{C}\right), \mathrm{SnO}_{2} \mathrm{NPs}$ $\left(390^{\circ} \mathrm{C}\right)$ and bulk $\mathrm{SnO}_{2}\left(475^{\circ} \mathrm{C}\right)$. Similarly, the apparent activation energy of these samples also gives the similar tendency. The outstanding performance of 0.6 -nm-thick $\mathrm{SnO}_{2}$ nanosheets could be ascribed to the extremely high specific surface area. Both the Sn and O atoms at surface sites have unsaturated coordination numbers that are favourable for $\mathrm{CO}$ catalytic oxidation, which is further confirmed by the density functional theory (DFT) calculations ${ }^{64}$.
Catalytic conversion of $\mathrm{CO}_{2}$ to $\mathrm{CH}_{4}$. The conversion of $\mathrm{CO}_{2}$ to $\mathrm{CH}_{4}$ fuel is of great importance to address both of the global warming and the energy-shortage problems ${ }^{85}$. As a typical example, Zou and co-workers presented that the ultrathin $\mathrm{WO}_{3}$ nanosheet could be a good photocatalyst for the reduction of $\mathrm{CO}_{2}$ to $\mathrm{CH}_{4}$ with $\mathrm{H}_{2} \mathrm{O}$ (ref. 70). It was found that $\mathrm{CO}_{2}$ and $\mathrm{H}_{2} \mathrm{O}$ can react with the photogenerated electrons and holes in the $\mathrm{WO}_{3}$ nanosheets under visible light irradiation to produce $\mathrm{CH}_{4}$ and $\mathrm{O}_{2}$ in comparison with the neglectable efficiency of the commercial $\mathrm{WO}_{3}$ powder. It is suggested that the enhanced performance for photocatalytic reduction of $\mathrm{CO}_{2}$ with $\mathrm{H}_{2} \mathrm{O}$ to hydrocarbon fuels is attributed to the size-quantization effect-induced change of $\mathrm{WO}_{3}$ band gap in this ultrathin 2D nanostructure. In addition, the ultrathin thickness of $\mathrm{WO}_{3}$ sheets is also beneficial for the fast charge mobility from the catalyst surface of the reactive agents (for example, $\mathrm{CO}_{2}$ and $\mathrm{H}_{2} \mathrm{O}$ ) during the photoreduction process.

Supercapacitors. Supercapacitor has been recognized as one of the most promising energy-storage devices because of its high power density, fast charging time and long lifetime ${ }^{86}$. It is expected that some ultrathin $2 \mathrm{D}$ nanosheets, especially metal hydroxides or oxides, with ultrahigh specific surface area could be attractive electrodes for high-performance supercapacitors ${ }^{87}$. As a typical example, Xie and co-workers reported the fabrication of all-solid-state asymmetric supercapacitor with ultrahigh energy density based on the single-layer $\beta-\mathrm{Co}(\mathrm{OH})_{2}$ nanosheet (Fig. 5) ${ }^{80}$. The single-layer $\beta$ - $\mathrm{Co}(\mathrm{OH})_{2}$ electrode gave a higher specific capacitance $\left(2,028 \mathrm{Fg}^{-1}\right)$, as compared with the 7 -nm-thick $\beta-\mathrm{Co}(\mathrm{OH})_{2}$ nanosheet $\left(998 \mathrm{Fg}^{-1}\right)$ and bulk $\beta-\mathrm{Co}(\mathrm{OH})_{2}$ electrodes $\left(525 \mathrm{Fg}^{-1}\right)$. The high specific capacitance of single-layer $\beta-\mathrm{Co}(\mathrm{OH})_{2}$ nanosheets could be attributed to its ultrahigh specific surface area that enables it with all hydrogen atom-exposed surface. Moreover, the single-layer $\beta-\mathrm{Co}(\mathrm{OH})_{2}$ nanosheet was used as the cathode to fabricate all-solid-state asymmetric supercapacitor device, in which the $\mathrm{N}$-doped graphene was the anode. The fabricated cell exhibited specific capacitance of $241.9,236.3,231.8,225.7$ and $219.6 \mathrm{Fg}^{-1}$ at the current density of $1,2,5,10$ and $20 \mathrm{Ag}^{-1}$ (Fig. 5b), respectively. Importantly, its specific energy density decreased from 108.9 to $98.9 \mathrm{Wh} \mathrm{kg}^{-1}$, while the power density increased from 0.9 to $17.98 \mathrm{~kW} \mathrm{~kg}^{-1}$ as the current density increased from 1 to $20 \mathrm{Ag}^{-1}$ (Fig. 5c). Even after 10,000 cycles, its capacitance still remained $93.2 \%$ at the scan rate of $20 \mathrm{mV} \mathrm{s}^{-1}$ (Fig. 5d), indicating its good cycling stability. Recently, Li and co-workers demonstrated that the ultrathin $\mathrm{NiO}$ nanosheets have good performance in supercapacitors ${ }^{58}$. It delivered high specific capacitance of $2,236 \mathrm{Fg}^{-1}$ at $0.5 \mathrm{Ag}^{-1}$. Even at higher current density, the specific capacitance is still maintained, that is, $1,392 \mathrm{Fg}^{-1}$ at $12 \mathrm{Ag}^{-1}$, and $1,576 \mathrm{Fg}^{-1}$ at $4 \mathrm{Ag}^{-1}$ with $99.1 \%$ retention after 2,000 cycles, suggesting good rate capability and excellent cycling stability. Although the $\mathrm{NiO}$ nanosheets present good performance in supercapacitor, its performance is not as good as the layered $\alpha-\mathrm{Ni}(\mathrm{OH})_{2}$ nanosheets $^{58}$.

Photodetectors. It was reported that the prepared PbS nanosheets can be readily integrated in a photodetector device without further treatment ${ }^{68}$. The $\mathrm{PbS}$ sheet-based device exhibited low conductance in dark without substantial hysteresis (Fig. 6a). The conductance increased by more than two orders of magnitude under illumination of $532-\mathrm{nm}$ laser at intensity of $2.0 \mathrm{~mW} \mathrm{~cm}^{-2}$ (Fig. 6a). A responsivity value of $0.472 \mathrm{AW}^{-1}$ at $0.1 \mathrm{~V}$ was achieved. Recently, Dou and co-workers demonstrated that ultrathin 2D metal oxide nanosheets can be used as the active layers to integrate into transparent and flexible ultraviolet photodetectors (Fig. $6 \mathrm{~b}-\mathrm{d})^{60}$. First of all, the single-layer 
a
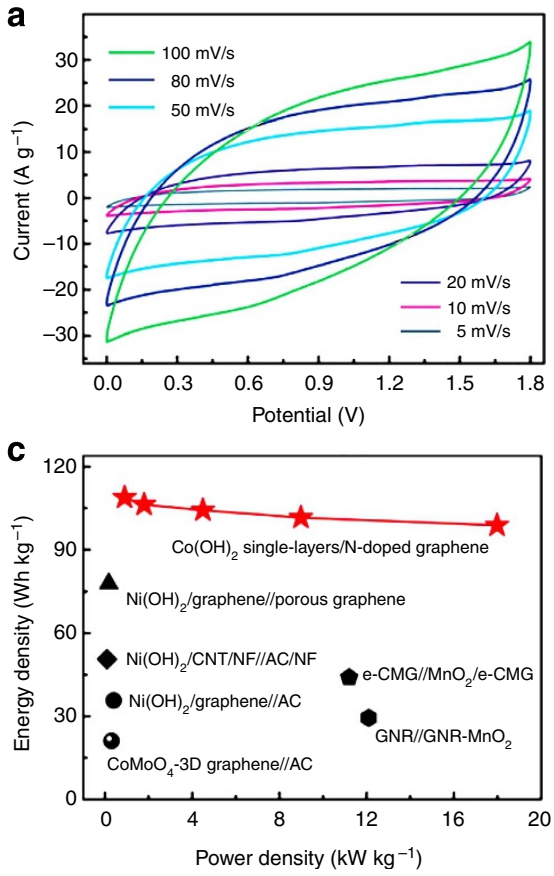
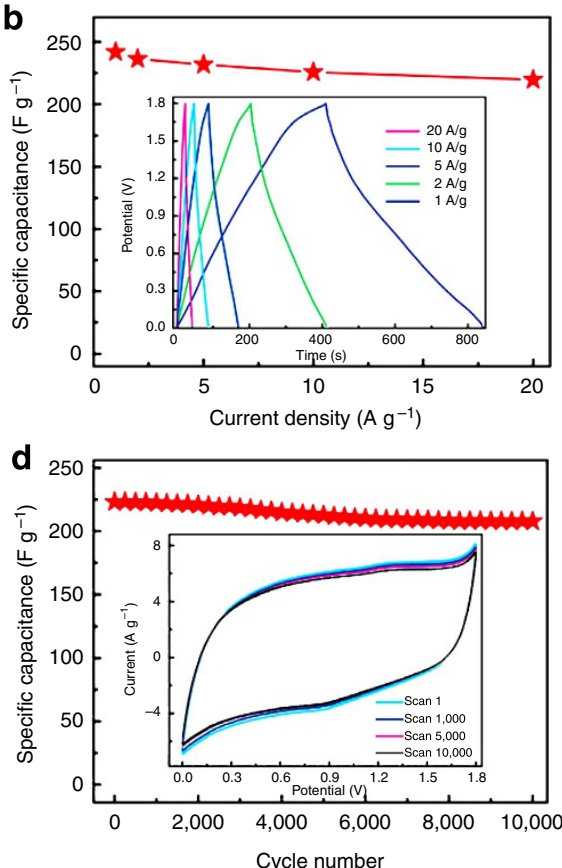

Figure 5 | Performance of the $\boldsymbol{\beta}-\mathbf{C o}(\mathbf{O H})_{2}$ nanosheet-based supercapacitor. (a) Cyclic voltammetry (CV) curves at various scan rates and (b) galvanostatic charge-discharge curves at different current densities (inset) and the corresponding calculated specific capacitances of the single-layer $\beta$ - $\mathrm{Co}(\mathrm{OH})_{2}$ nanosheet-based all-solid-state asymmetric supercapacitor. (c) Comparison of the electrochemical performance with previously reported asymmetric supercapacitors. (d) Cycling performance of the fabricated single-layer $\beta$ - $\mathrm{Co}(\mathrm{OH})_{2}$ nanosheet-based all-solid-state asymmetric supercapacitor measured at a scan rate of $20 \mathrm{mVs}^{-1}$. Inset: the corresponding CV curves. Reproduced, with permission, from ref. 80 ((C) 2014 John Wiley \& Sons Inc).

CVD-grown graphene was transferred on a flexible polyethylene terephthalate substrate as the back electrode. Then, the suspension of ultrathin 2D metal oxide nanosheets in ethanol was spin-coated on the graphene electrode to form transparent and flexible photoelectrode (Fig. 6b). The deposited 2D metal oxide nanosheet layer has thickness of $\sim 50 \mathrm{~nm}$. The photocurrent responses of the ultraviolet photodetectors were tested under $325-\mathrm{nm}$ ultraviolet light $\left(67 \mathrm{~mW} \mathrm{~cm}^{-2}\right)$ or an alternating ON and OFF ultraviolet source with interval of $10 \mathrm{~s}$. The photocurrent density of the ultrathin 2D metal oxide nanosheet-based photodetectors could reach the order of $\mathrm{mA} \mathrm{cm}{ }^{-2}$. The $\mathrm{WO}_{3}$ photodetector showed a typical $p$-type Schottky barrier contact, while the others exhibited obvious ohmic behaviours with perfect linear current-voltage $(I-V)$ responses under the ultraviolet irradiation (Fig. $6 \mathrm{c}$,d). Note that all the ultrathin metal oxide nanosheet-based devices showed much enhanced photocurrent under the ultraviolet irradiation, indicating that $\mathrm{TiO}_{2}, \mathrm{ZnO}$ and $\mathrm{Co}_{3} \mathrm{O}_{4} 2 \mathrm{D}$ ultrathin nanosheets are promising candidates for fabrication of high-performance and low-cost photodetectors. More importantly, all the devices presented high stability and reproducibility towards the time response. Even after tens of ON/OFF switching cycles, no obvious degradation was detected, proving the excellent stability of the fabricated devices.

Photothermal therapy. Photothermal therapy is to use the laser irradiation-generated heat to induce hyperthermia within tumour tissues, thus causing the denaturation of proteins, the disruption of cell membrane and subsequent killing of cancer cells $s^{88}$. For example, Zheng and co-workers demonstrated that the $\mathrm{Pd}$ nanosheet could be a promising photothermal agent for photothermal therapy for cancer ${ }^{81}$. The Pd nanosheets with controllable edge length exhibited the tunable and strong SPR absorption $(826-1,068 \mathrm{~nm})$ and high stability on the near-infrared (NIR) irradiation, and those with edge size of $41 \mathrm{~nm}$ presented the extinction coefficient of as high as $4.1 \times 10^{9} \mathrm{M}^{-1} \mathrm{~cm}^{-1}$ at $1,045 \mathrm{~nm}$. The temperature of $1 \mathrm{ml}$ aqueous solution containing 27-p.p.m. Pd nanosheets could rise from 28.0 to $48.7^{\circ} \mathrm{C}$ after 10 -min irradiation by a NIR laser $\left(808 \mathrm{~nm}, 1 \mathrm{~W} \mathrm{~cm}^{-2}\right)$. The significant in vitro photothermal cell-killing effect has been achieved by using the Pd nanosheet as the photothermal agent on irradiation of $808 \mathrm{~nm}$ laser. More importantly, the Pd nanosheet also exhibited enhanced photothermal stability in comparison with $\mathrm{Ag}$ and $\mathrm{Au}$ nanostructures with the NIR photothermal effect ${ }^{81}$.

\section{Future prospects}

This review summarizes the recent progress on the wet-chemical preparation and applications of non-layer structured ultrathin 2D nanomaterials. A number of effective wet-chemical methods have so far been developed to prepare non-layer structured 2D nanomaterials (for example, metals, metal oxides and metal chalcogenides) in high yield, large scale and low cost. Excellent performances of these synthesized ultrathin 2D nanosheets for some important applications, especially in catalysis (for example, catalytic organic reactions and CO oxidation), have been demonstrated. From the point of view of the synthesis method, the 2D-templated synthesis method has been proved to be one of the most promising strategies. For example, by using layered or easily prepared $2 \mathrm{D}$ nanomaterials as templates, novel non-layerstructured 2D nanomaterials could be prepared through the proper chemical transformation methods such as cation exchange and oxidation. In such processes, the $2 \mathrm{D}$ morphology originated from the templating materials could be remained after the chemical transformation. In addition, the hydro/solvothermal synthesis is another appealing approach to synthesize non-layerstructured 2D nanomaterials, in which the experimental parameters, such as the concentration of precursors, solvent, reaction temperature and surfactants, are important factors. 


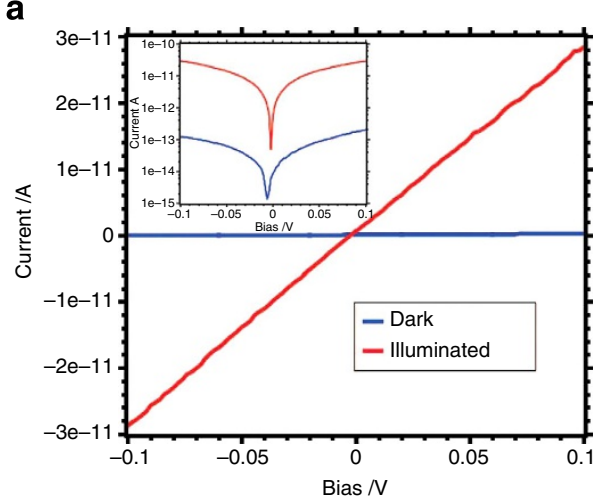

b

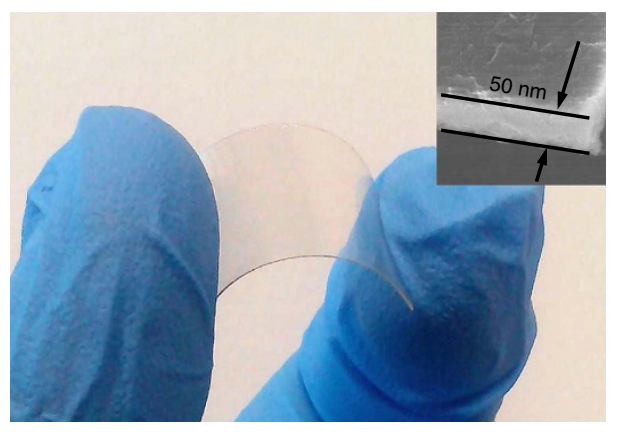

C

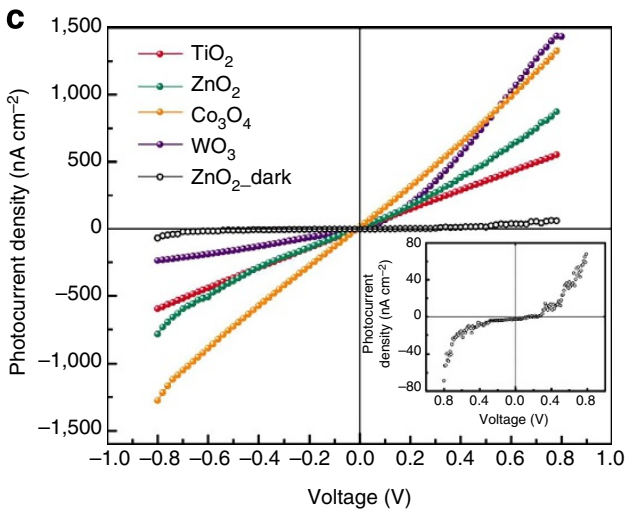

d

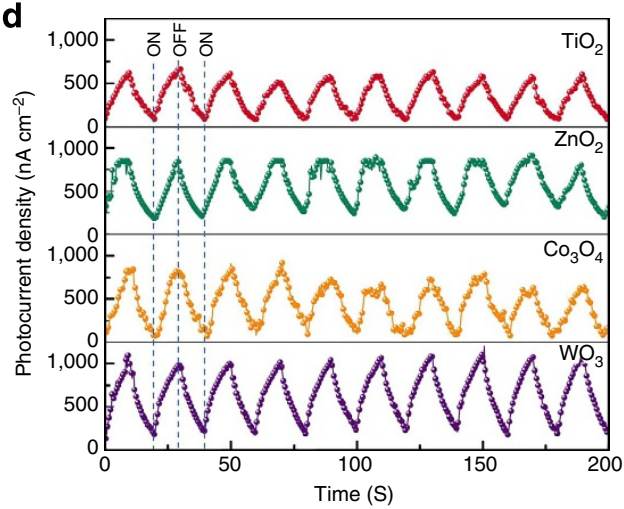

Figure 6 | Performance of 2D nanosheet-based photodetectors. (a) Current-voltage curves of PbS sheets in dark (red) and under illumination (blue) with a green laser. Inset: current-voltage curves on the logarithmic scale. From ref. 68. Reprinted from permission from AAAS. (b) Photograph of the flexibility demonstration of the fabricated electrode. Inset: SEM cross-section image of a typical photoelectrode. (c) I- $V$ characteristics of photodetectors based on $2 \mathrm{D}$ nanosheets of $\mathrm{TiO}_{2}, \mathrm{ZnO}, \mathrm{Co}_{3} \mathrm{O}_{4}$ and $\mathrm{WO}_{3}$, respectively. Inset: $I-V$ characteristic of the dark photocurrent of $2 \mathrm{D} \mathrm{ZnO}$ nanosheet photoanode.

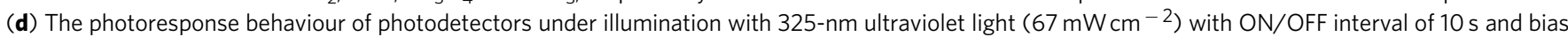
of $0.5 \mathrm{~V}$. Adapted from ref. 60.

Therefore, systematic studies need to be conducted to optimize the experimental conditions to achieve the synthesis of new non-layer structured 2D nanostructures.

Currently, most reported wet-chemical methods are only applicable to synthesize specific materials with uncontrollable size, thickness and crystal phase. Despite that some pioneer work has been conducted, challenges still remain in this field. First, it is difficult to synthesize single-layer nanosheets for most non-layer structured materials by wet-chemical methods. Second, the lateral sizes of most non-layer structured 2D nanomaterials synthesized using wet-chemical methods are less than $1 \mu \mathrm{m}$, which is relatively small compared with the nanosheets prepared by exfoliation methods or CVD growth. Last, surfactants are always required during the synthesis process, which are undesirable for some further applications, especially for catalysis and electronic devices. Therefore, it is critical and urgent to find a general and effective way for controlled synthesis of ultrathin non-layer structured 2D nanomaterials. Meanwhile, the mechanisms underlying the crystal growth of ultrathin $2 \mathrm{D}$ nanomaterials remain unclear. Therefore, finding simple and efficient techniques for exploration of the mechanism behind these crystal growth processes is also a pressing topic. In addition, most researchers are focusing on producing ultrathin 2D nanomaterials and then demonstrating proof-of-concept applications. Little attention has been paid on the rational design of a material with desired lateral size, thickness, defect, crystal phase and structure. It is well known that the aforementioned structural parameters have significant effect on the performance of a material for specific application. Meanwhile, the favourable structural parameters vary for different applications. Therefore, one of the most challenging fact lies in how we can realize desired performance towards specific application via the rational design of an ultrathin $2 \mathrm{D}$ nanostructure with favourable size, thickness, surface state and defect at a highly controllable level.

It is noteworthy that the wet-chemical synthesis of non-layerstructured ultrathin 2D nanomaterials is still in its infant stage. On one hand, there are still a lot of materials whose ultrathin nanosheets have not been synthesized. For example, it is well known that $\mathrm{Pt}$ is one of the most robust catalysts for some electrocatalytic reactions (for example, hydrogen evolution and oxygen reduction reaction $)^{89,90}$. It is anticipated that ultrathin $\mathrm{Pt}$ nanosheets, which have not been synthesized yet, could exhibit excellent catalytic activities for these electrocatalytic processes. Bearing this in mind, one of the future directions is to develop efficient methods for preparation of novel ultrathin 2D nanosheets in single component or multicomponents (for example, alloy), which could possess promising properties and advanced functions. On the other hand, previous studies have demonstrated that the incorporation of other nanomaterials, such as noble metals, metal oxides, semiconductors and polymers, with ultrathin 2D nanosheets (for example, graphene and transition metal dichalcogenide nanosheets) to construct advanced functional composites is a very promising way to further optimize their properties and achieve their superior performances for a wide range of applications ${ }^{91-100}$. Inspiringly, another promising future direction in this field is the construction 
of functional hybrid nanomaterials on the basis of these synthesized non-layer structured ultrathin $2 \mathrm{D}$ nanosheets to achieve desired performance for numerous applications.

\section{References}

1. Novoselov, K. S. et al. Electric field effect in atomically thin carbon films. Science 306, 666-669 (2004).

2. Geim, A. K. \& Novoselov, K. S. The rise of graphene. Nat. Mater. 6, 183-191 (2007).

3. Chhowalla, M. et al. The chemistry of two-dimensional layered transition metal dichalcogenide nanosheets. Nat. Chem. 5, 263-275 (2013).

4. Xu, M. S., Liang, T., Shi, M. M. \& Chen, H. Z. Graphene-like two-dimensional materials. Chem. Rev. 113, 3766-3798 (2013).

5. Nicolosi, V., Chhowalla, M., Kanatzidis, M. G., Strano, M. S. \& Coleman, J. N. Liquid exfoliation of layered materials. Science 340, 1226419 (2013).

6. Allen, M. J., Tung, V. C. \& Kaner, R. B. Honeycomb carbon: a review of graphene. Chem. Rev. 110, 132-145 (2010).

7. Wang, Q. H., Kalantar-Zadeh, K., Kis, A., Coleman, J. N. \& Strano, M. S Electronics and optoelectronics of two-dimensional transition metal dichalcogenides. Nat. Nanotech. 11, 699-712 (2012).

8. Huang, X., Zeng, Z. Y. \& Zhang, H. Metal dichalcogenide nanosheets: preparation, properties and applications. Chem. Soc. Rev. 42, 1934-1946 (2013).

9. Sun, Y. F., Gao, S. \& Xie, Y. Atomically-thick two-dimensional crystals electronic structure regulation and energy device construction. Chem. Soc. Rev. 43, 530-546 (2014).

10. Naguib, M. et al. Two-dimensional transition metal carbides. ACS Nano 6, 1322-1331 (2012).

11. Zhang, X. D. et al. Recent advances in free-standing two-dimensional crystals with atomic thickness: design, assembly and transfer strategies. Chem. Soc. Rev. 42, 8187-8199 (2013).

12. Sun, Y. F. et al. Ultrathin two-dimensional inorganic materials: new opportunities for solid state nanochemistry. Acc. Chem. Res. 48, 3-12 (2015).

13. Radisavljevic, B., Radenovic, A., Brivio, J., Giacometti1, V. \& Kis, A. Single-layer $\mathrm{MoS}_{2}$ transistors. Nat. Nanotech. 6, 147-150 (2011).

14. Yin, Z. Y. et al. Single-layer $\mathrm{MoS}_{2}$ phototransistors. ACS Nano 6, 74-80 (2012).

15. Liang, L. et al. Vacancy associates-rich ultrathin nanosheets for high performance and flexible nonvolatile memory device. J. Am. Chem. Soc. 137, 3102-3108 (2015).

16. Song, F. \& Hu, X. L. Exfoliation of layered double hydroxides for enhanced oxygen evolution catalysis. Nat. Commun. 5, 4477 (2013).

17. Voiry, D. et al. Enhanced catalytic activity in strained chemically exfoliated $\mathrm{WS}_{2}$ nanosheets for hydrogen evolution. Nat. Mater. 12, 850-855 (2013).

18. Yang, S. B. et al. Exfoliated graphitic carbon nitride nanosheets as efficient catalysts for hydrogen evolution under visible light. Adv. Mater. 25, 2452-2456 (2013).

19. Du, G. D. et al. Superior stability and high capacity of restacked molybdenum disulfide as anode material for lithium ion batteries. Chem. Commun. 46, 1106-1108 (2010).

20. Tsai, M. L. et al. Monolayer $\mathrm{MoS}_{2}$ heterojunction solar cells. ACS Nano 8, 8317-8322 (2014)

21. Zhu, C. F. et al. Single-layer $\mathrm{MoS}_{2}$-based nanoprobes for homogeneous detection of biomolecules. J. Am. Chem. Soc. 135, 5998-6001 (2013).

22. Perkins, F. K. et al. Chemical vapor sensing with monolayer $\mathrm{MoS}_{2}$. Nano Lett. 13, 668-673 (2013)

23. Cheng, L. et al. PEGylated $\mathrm{WS}_{2}$ nanosheets as a multifunctional theranostic agent for in vivo dual-modal CT/photoacoustic imaging guided photothermal therapy. Adv. Mater. 26, 1886-1893 (2014).

24. Novoselov, K. S. et al. Two-dimensional atomic crystals. Proc. Natl Acad. Sci. USA 102, 10451-10453 (2005).

25. Li, H., Wu, J., Yin, Z. Y. \& Zhang, H. Preparation and applications of mechanically exfoliated single- and multi-layer $\mathrm{MoS}_{2}$ and $\mathrm{WSe}_{2}$ nanosheets. Acc Chem. Res. 47, 1067-1075 (2014).

26. Li, H. et al. Mechanical exfoliation and characterization of single- and few-layer nanosheets of $\mathrm{WSe}_{2}, \mathrm{TaS}_{2}$, and $\mathrm{TaSe}_{2}$. Small 9, 1974-1981 (2013).

27. Hernandez, Y. et al. High-yield production of graphene by liquid-phase exfoliation of graphite. Nat. Nanotech. 3, 563-568 (2008).

28. Coleman, J. N. et al. Two-dimensional nanosheets produced by liquid exfoliation of layered materials. Science 331, 568 (2011).

29. Wang, H. et al. Half-metallicity in single-layered manganese dioxide nanosheets by defect engineering. Angew. Chem. Int. Ed. 54, 1195-1199 (2015).

30. Zhi, C. Y., Bando, Y., Tang, C. C., Kuwahara, H. \& Golberg, D. Large-scale fabrication of boron nitride nanosheets and their utilization in polymeric composites with improved thermal and mechanical properties. Adv. Mater. 21, 2889 (2009).
31. Dines, M. B. Lithium intercalation via $n$-butyllithium of the layered transition metal dichalcogenides. Mater. Res. Bull. 10, 287-291 (1975).

32. Joensen, P., Frindt, R. F. \& Morrison, S. R. Single-layer $\mathrm{MoS}_{2}$. Mater. Res. Bull. 21, 457-461 (1986).

33. Zeng, Z. Y. et al. Single-layer semiconducting nanosheets: high-yield preparation and device fabrication. Angew. Chem. Int. Ed. 50, 11093-11097 (2011).

34. Zeng, Z. Y. et al. An effective method for the fabrication of few-layer-thick inorganic nanosheets. Angew. Chem. Int. Ed. 51, 9052-9056 (2012).

35. Zhang, J. et al. High yield exfoliation of two-dimensional chalcogenides using sodium naphthalenide. Nat. Commun. 5, 2995 (2014).

36. Li, X. S. et al. Large-area synthesis of high-quality and uniform graphene films on copper foils. Science 324, 1312-1314 (2009).

37. Lee, Y. H. et al. Synthesis of large-area $\mathrm{MoS}_{2}$ atomic layers with chemical vapor deposition. Adv. Mater. 24, 2320-2325 (2012).

38. Ji, Q. Q., Zhang, Y., Zhang, Y. F. \& Liu, Z. F. Chemical vapour deposition of group-VIB metal dichalcogenide monolayers: engineered substrates from amorphous to single crystalline. Chem. Soc. Rev. 44, 2587-2602 (2015).

39. Song, L. et al. Large scale growth and characterization of atomic hexagonal boron nitride layers. Nano Lett. 10, 3209-3215 (2010).

40. Shi, Y. M., Li, H. N. \& Li, L.-J. Recent advances in controlled synthesis of two-dimensional transition metal dichalcogenides via vapour deposition techniques. Chem. Soc. Rev. 44, 2744-2756 (2015).

41. Yoo, D., Kim, M., Jeong, S., Han, J. \& Cheon, J. Chemical synthetic strategy for single-layer transition-metal chalcogenides. J. Am. Chem. Soc. 136, 14670-14673 (2014)

42. Mahler, B., Hoepfner, V., Liao, K. \& Ozin, G. A. Colloidal synthesis of 1T-WS and $2 \mathrm{H}-\mathrm{WS}_{2}$ nanosheets: applications for photocatalytic hydrogen evolution. J. Am. Chem. Soc. 136, 14121-14127 (2014)

43. Xie, J. F. et al. Controllable disorder engineering in oxygen-incorporated $\mathrm{MoS}_{2}$ ultrathin nanosheets for efficient hydrogen evolution. J. Am. Chem. Soc. 135, 17881-17888 (2013).

44. Son, J. S. et al. Colloidal synthesis of ultrathin two-dimensional semiconductor nanocrystals. Adv. Mater. 23, 3214-3219 (2011)

45. Bi, W. T. et al. CuInSe ${ }_{2}$ ultrathin nanoplatelets: novel self-sacrificial template-directed synthesis and application for flexible photodetectors. Chem. Commun. 48, 9162-9164 (2012).

46. Vaughn, II D. D., In, S.-I. \& Schaak, R. E. A precursor-limited nanoparticle coalescence pathway for tuning the thickness of laterally-uniform colloidal nanosheets: the case of SnSe. ACS Nano 5, 8852-8860 (2011).

47. Yin, A. X. et al. Ru nanocrystals with shape-dependent surface-enhanced Raman spectra and catalytic properties: controlled synthesis and DFT calculations. J. Am. Chem. Soc. 134, 20479-20489 (2012).

48. Saleem, F. et al. Ultrathin Pt-Cu nanosheets and nanocones. J. Am. Chem. Soc 135, 18304-18307 (2013).

49. Fullam, S., Cottell, D., Rensmo, H. \& Fitzmaurice, D. Carbon nanotube templated self-assembly and thermal processing of gold nanowires. Adv. Mater. 12, 1430-1432 (2000).

50. Cao, G. Z. \& Liu, D. W. Template-based synthesis of nanorod, nanowire, and nanotube arrays. Adv. Colloid. Interface 136, 45-64 (2008).

51. Huang, X. et al. Synthesis of hexagonal close-packed gold nanostructures. Nat Commun. 2, 292 (2011)

This paper presents the first achievement on the synthesis of pure ultrathin hexagonal close-packed gold squire sheets that are stable at ambient conditions by the wet-chemical synthesis method.

52. Huang, X. et al. Synthesis of gold square-like plates from ultrathin gold square sheets: the evolution of structure phase and shape. Angew. Chem. Int. Ed. 50, 12245-12248 (2011)

53. Fan, Z. X. et al. Surface modification-induced phase transformation of hexagonal close-packed gold square sheets. Nat. Commun. 6, 6571 (2015). This paper gives the first example on the surface modification such as ligand exchange and metal coating induced phase transformation from the hexagonal close-packed phase to face-centered cubic phase at room temperature and ambient conditions

54. Fan, Z. X. et al. Synthesis of ultrathin $f c c$ Au@Pt and Au@Pd core-shell nanoplates from hcp Au square sheets. Angew. Chem. Int. Ed. 127, 5764-5768 (2015).

55. Cheng, W. R. et al. Half-unit-cell $\alpha-\mathrm{Fe}_{2} \mathrm{O}_{3}$ semiconductor nanosheets with intrinsic and robust ferromagnetism. J. Am. Chem. Soc. 136, 10393-10398 (2014).

56. Wu, X. J. et al. Copper-based ternary and quaternary semiconductor nanoplates: templated synthesis, characterization, and photoelectrochemical properties. Angew. Chem. Int. Ed. 53, 8929-8933 (2014).

57. Wu, X. J. et al. Two-dimensional CuSe nanosheets with microscale lateral size: synthesis and template-assisted phase transformation. Angew. Chem. Int. Ed. 53, 5083-5087 (2014) 
58. Zhu, Y. Q. et al. Ultrathin nickel hydroxide and oxide nanosheets: synthesis, characterizations and excellent supercapacitor performances. Sci. Rep. 4, 5787 (2014).

59. Duan, H. H. et al. Ultrathin rhodium nanosheets. Nat. Commun. 5, 3093 (2014).

This paper reports the first example on synthesis of single-layer rhodium nanosheets by a solvothermal method with excellent catalytic activities for catalytic organic reactions

60. Sun, Z. Q. et al. Generalized self-assembly of scalable two-dimensional transition metal oxide nanosheets. Nat. Commun. 5, 3813 (2014).

This paper presents a general route for the synthesis of a series of non-layer structured metal oxide nanosheets including $\mathrm{TiO}_{2}, \mathrm{ZnO}, \mathrm{Co}_{3} \mathrm{O}_{4}, \mathrm{WO}_{3}, \mathrm{Fe}_{3} \mathrm{O}_{4}$ and $\mathrm{MnO}_{2}$ in solution phase.

61. Sun, Y. F. et al. Fabrication of flexible and freestanding zinc chalcogenide single layers. Nat. Commun. 3, 1057 (2012).

62. Sun, Y. F. et al. Pits confined in ultrathin cerium(IV) oxide for studying catalytic centers in carbon monoxide oxidation. Nat. Commun. 4, 2899 (2013).

This paper reports the synthesis of pits confined in ultrathin cerium(IV) oxide nanosheets as highly efficient catalysts for oxidation of carbon monoxide.

63. Lei, F. C. et al. Oxygen vacancies confined in ultrathin indium oxide porous sheets for promoted visible-light water splitting. J. Am. Chem. Soc. 136, 6826-6829 (2014)

64. Sun, Y. F. et al. Atomically thin tin dioxide sheets for efficient catalytic oxidation of carbon monoxide. Angew. Chem. Int. Ed. 52, 10569-10572 (2013).

65. Zhang, X. D. et al. Half-metallic ferromagnetism in synthetic $\mathrm{Co}_{9} \mathrm{Se}_{8}$ nanosheets with atomic thickness. J. Am. Chem. Soc. 134, 11908-11911 (2012).

66. Zhang, X. D. et al. In-plane coassembly route to atomically thick inorganic-organic hybrid nanosheets. ACS Nano 7, 1682-1688 (2013).

67. Xu, Y., Zhao, W. W., Xu, R., Shi, Y. M. \& Zhang, B. Synthesis of ultrathin CdS nanosheets as efficient visible-light-driven water splitting photocatalysts for hydrogen evolution. Chem. Commun. 49, 9803-9805 (2013).

68. Schliehe, C. et al. Ultrathin $\mathrm{PbS}$ sheets by two-dimensional oriented attachment. Science 329, 550 (2010).

This paper first reports the synthesis of non-layer structured ultrathin PbS nanosheets by two-dimensional oriented attachment from PbS tiny nanoparticles.

69. Wang, Z. W. et al. Deviatoric stress driven formation of large single-crystal $\mathrm{PbS}$ nanosheet from nanoparticles and in situ monitoring of oriented attachment. J. Am. Chem. Soc. 133, 14484-14487 (2011).

70. Chen, X. Y. et al. Ultrathin, single-crystal $\mathrm{WO}_{3}$ nanosheets by twodimensional oriented attachment toward enhanced photocatalystic reduction of $\mathrm{CO}_{2}$ into hydrocarbon fuels under visible light. ACS Appl. Mater. Interfaces 4, 3372-3377 (2012).

71. Wu, Z. N. et al. Self-assembly of $\mathrm{Au}_{15}$ into single-cluster-thick sheets at the interface of two miscible high-boiling solvents. Angew. Chem. Int. Ed. 52, 9952-9955 (2013).

72. Zhong, Y. T., Yang, Y. J., Ma, Y. \& Yao, J. N. Controlled synthesis of ultrathin lamellar $\mathrm{Eu}_{2} \mathrm{O}_{3}$ nanocrystals: self-assembly of $1 \mathrm{D}$ nanowires to $2 \mathrm{D}$ nanosheets. Chem. Commun. 49, 10355-10357 (2013).

73. Acharya, S. et al. A bottom-up approach toward fabrication of ultrathin $\mathrm{PbS}$ sheets. Nano Lett. 13, 409-415 (2013).

74. Ithurria, S. et al. Colloidal nanoplatelets with two-dimensional electronic structure. Nat. Mater. 10, 936-941 (2011).

75. Ithurria, S. \& Dubertret, B. Quasi 2D colloidal CdSe platelets with thicknesses controlled at the atomic level. J. Am. Chem. Soc. 130, 16504-16505 (2008).

76. Son, J. S. et al. Large-scale soft colloidal template synthesis of $1.4 \mathrm{~nm}$ thick CdSe nanosheets. Angew. Chem. Int. Ed. 48, 686-6864 (2009).

77. Du, Y. P. et al. A general method for the large-scale synthesis of uniform ultrathin metal sulphide nanocrystals. Nat. Commun. 3, 1177 (2012).

This paper reports the first synthesis of ultrathin hexagonal CuS nanosheets with uniform size and thickess by the soft colloidal templated synthesis method.

78. Li, L. et al. Single-layer single-crystalline SnSe nanosheets. J. Am. Chem. Soc. 135, 1213-1216 (2013)

79. Zhang, Q. \& Yan, B. Salt-effect-based synthesis and anomalous magnetic properties of rare-earth oxide nanosheets with sub-1 nm thickness. Chem. Eur. J. 18, 5150-5154 (2012).

80. Gao, S. et al. Ultrahigh energy density realized by a single-layer $\beta-\mathrm{Co}(\mathrm{OH})_{2}$ all-solid-state asymmetric supercapacitor. Angew. Chem. Int. Ed. 53, 12789-12793 (2014).

This paper reports the fabrication of high-performance all-solid-state asymmetric supercapacitor devices based on single-layer $\mathrm{\beta}-\mathrm{Co}(\mathrm{OH})_{2}$ nanosheets.
81. Huang, X. Q. et al. Freestanding palladium nanosheets with plasmonic and catalytic properties. Nat. Nanotech. 6, 28-32 (2011).

This paper reports a CO-confined growth method for synthesis of freestanding ultrathin hexagonal palladium nanosheets with a thickness less than 10 atomic layers and a controllable edge length from 20 to $160 \mathrm{~nm}$.

82. Stoller, M. D., Park, S., Zhu, Y., An, J. \& Ruoff, R. S. Graphene-based ultracapacitors. Nano Lett. 8, 3498-3502 (2008).

83. Morales-Guio, C. G., Stern, L.-A. \& Hu, X. L. Nanostructured hydrotreating catalysts for electrochemical hydrogen evolution. Chem. Soc. Rev. 43, 6555-6569 (2014)

84. Sun, Y. F., Gao, S., Lei, F. C. \& Xie, Y. Atomically-thin two-dimensional sheets for understanding active sites in catalysis. Chem. Soc. Rev. 44, 623-636 (2015).

85. Roy, S. C., Varghese, O. K., Paulose, M. \& Grimes, C. A. Toward solar fuels photocatalytic conversion of carbon dioxide to hydrocarbons. ACS Nano 4, 1259-1278 (2010).

86. Simon, P. \& Gogotsi, Y. Materials for electrochemical capacitors. Nat. Mater. 7, 845-854 (2008)

87. Wang, Q. \& O'Hare, D. Recent advances in the synthesis and application of layered double hydroxide (LDH) nanosheets. Chem. Rev. 112, 4124-4155 (2012).

88. Lal, S., Clare, S. E. \& Halas, N. J. Nanoshell-enabled photothermal cancer therapy: impending clinical impact. Acc. Chem. Res. 41, 1842-1851 (2008)

89. Chen, A. C. \& Holt-Hindle, P. Platinum-based nanostructured materials: synthesis, properties, and applications. Chem. Rev. 110, 3767-3804 (2010).

90. Peng, Z. M. \& Yang, H. Designer platinum nanoparticles: control of shape, composition in alloy, nanostructure and electrocatalytic property. Nano Today 4, 143-164 (2009)

91. Stankovich, S. et al. Graphene-based composite materials. Nat. Mater. 442, 282-286 (2006).

92. Huang, X., Qi, X. Y., Boey, F. \& Zhang, H. Graphene-based composites. Chem. Soc. Rev. 41, 666-686 (2012).

93. Tan, C. L. \& Zhang, H. Two-dimensional transition metal dichalcogenide nanosheet-based composites. Chem. Soc. Rev. 44, 2713-2731 (2015).

94. Huang, X. et al. Solution-phase epitaxial growth of noble metal nanostructures on dispersible single-layer molybdenum disulfide nanosheets. Nat. Commun. 4, 1444 (2013).

95. Kuilla, T. et al. Recent advances in graphene based polymer composites. Prog Polym. Sci. 35, 1350-1375 (2010)

96. Huang, X., Tan, C. L., Yin, Z. Y. \& Zhang, H. 25th Anniversary Article: hybrid nanostructures based on two-dimensional nanomaterials. Adv. Mater. 26, 2185-2204 (2014)

97. Li, Y. G. et al. Advanced zinc-air batteries based on high-performance hybrid electrocatalysts. Nat. Commun. 4, 1805 (2013).

98. Liang, Y. Y. et al. $\mathrm{Co}_{3} \mathrm{O}_{4}$ nanocrystals on graphene as a synergistic catalyst for oxygen reduction reaction. Nat. Mater. 10, 780-786 (2011).

99. Yang, J. et al. Two-dimensional hybrid nanosheets of tungsten disulfide and reduced graphene oxide as catalysts for enhanced hydrogen evolution. Angew. Chem. Int. Ed. 52, 13751-13754 (2013).

100. Tan, C. L. et al. Self-assembled chiral nanofibers from ultrathin lowdimensional nanomaterials. J. Am. Chem. Soc. 137, 1565-1571 (2015).

\section{Acknowledgements}

This work was supported by MOE under AcRF Tier 2 (ARC 26/13, No. MOE2013-T2-1-034), AcRF Tier 1 (RGT18/13 and RG5/13), NTU under Start-Up Grant (M4081296.070.500000) and iFood Research Grant (M4081458.070.5000000), Singapore Millennium Foundation, and National Research Foundation in Singapore. This Research is also conducted by NTU-HUJ-BGU Nanomaterials for Energy and Water Management Programme under the Campus for Research Excellence and Technological Enterprise (CREATE) that is supported by the National Research Foundation, Prime Minister's Office, Singapore.

\section{Additional information}

Competing financial interests: The authors declare no competing financial interests.

Reprints and permission information is available online at http://npg.nature.com/ reprintsandpermissions/

How to cite this article: Tan, C. and Zhang, H. Wet-chemical synthesis and applications of non-layer structured two-dimensional nanomaterials. Nat. Commun. 6:7873 doi: $10.1038 /$ ncomms8873 (2015)

This work is licensed under a Creative Commons Attribution 4.0 International License. The images or other third party material in this article are included in the article's Creative Commons license, unless indicated otherwise in the credit line; if the material is not included under the Creative Commons license, users will need to obtain permission from the license holder to reproduce the material. To view a copy of this license, visit http://creativecommons.org/licenses/by/4.0/ 